\title{
Shedding Light on Social Reward Circuitry: (Un)common Blueprints in Humans and Rodents
}

\section{Review Article}

Author(s):

Grimm, Christina; Balsters, Joshua Henk; Zerbi, Valerio (D)

Publication date:

2021-04-01

Permanent link:

https://doi.org/10.3929/ethz-b-000421439

Rights / license:

In Copyright - Non-Commercial Use Permitted

Originally published in:

The Neuroscientist 27(2), https://doi.org/10.1177/1073858420923552

Funding acknowledgement:

173984 - Pharmacogenetic fMRI in brain circuits underlying social motivation and repetitive behavior (SNF) 


\title{
Shedding Light on Social Reward Circuitry: (Un)common Blueprints in Humans and Rodents
}

The Neuroscientist

202I, Vol. 27(2) I59-I83

(C) The Author(s) 2020

Article reuse guidelines:

sagepub.com/journals-permissions DOI: I0.1 |77// 073858420923552 journals.sagepub.com/home/nro

(S)AGE

\author{
Christina Grimm', Joshua Henk Balsters², \\ and Valerio Zerbi ${ }^{\prime}$
}

\begin{abstract}
Human behavior is strongly influenced by our motivation to establish social relationships and maintain them throughout life. Despite the importance of social behavior across species, it is still unclear how neural mechanisms drive social actions. Rodent models have been used for decades to unravel the neural pathways and substrates of social interactions. With the advent of novel approaches to selectively modulate brain circuits in animal models, unprecedented testing of brain regions and neuromodulators that encode social information can be achieved. However, it is unclear which classes of social behavior and related neural circuits can be generalized across species and which are unique to humans. There is a growing need to define a unified blueprint of social brain systems. Here, we review human and rodent literature on the brain's social actuators, specifically focusing on social motivation. We discuss the potential of implementing multimodal neuroimaging to guide us toward a consensus of brain areas and circuits for social behavior regulation. Understanding the circuital similarity and diversity is the critical step to improve the translation of research findings from rodents to humans.
\end{abstract}

\section{Keywords}

social behavior, social reward, social motivation, fMRI, translational neuroimaging, rodent, human

\section{Introduction}

Why do humans engage and invest in social interactions? How do brain circuits drive us to act in a cooperative or competitive manner? Throughout this review, we define social behavior as any modality of communication and/or interaction between two or more conspecifics (Crespi 2001; Ebstein and others 2010). For this purpose, species-typical signals such as body language, facial expressions, or vocalizations act as mediators to build and maintain social bonding and social networks. However, social signals can display considerable variability across species, in part dictated by the individual's ability to recognize, evaluate, and possibly react to them. In social science the ability to infer what another conspecific is thinking, feeling or perceiving, is often referred to as "theory of mind" (Baron-Cohen and others 1985). In humans, research has shown that motivation to seek out social cues at an early age plays a key role in developing social skills such as theory of mind. Infants rapidly recognize faces and display a visual preference for them (Walton and Bower 1993). Particularly attending to and responding to gaze are crucial for successful joint attention as well as social orienting and ultimately guide the development of social relationships (Baron-Cohen 2000;
Williams and others 2001). Individuals who fail to extract and process social information as a result of impaired social motivation, might not experience social contact as positively reinforcing (rewarding) and are therefore less likely to pursue it in the future (Dawson and others 2002). These patterns are commonly observed in socially debilitating disorders like autism spectrum disorders (ASD) (Chevallier and others 2012), schizophrenia (Fulford and others 2018), and psychopathy (Lockwood 2016; Viding and McCrory 2019).

Humans are not the only species to display social seeking behaviors. Instead, several forms of sociality have evolved in non-human primates and rodents as well (Watson and Platt 2012). One hypothesis proposes that socal behavior, regardless of the nature of social signals,

'Neural Control of Movement Lab, HEST, ETH Zürich, Zurich, Switzerland

${ }^{2}$ Department of Psychology, Royal Holloway University of London, Egham, Surrey, UK

\section{Corresponding Author:}

Valerio Zerbi, Neural Control of Movement Lab, Department of Health Sciences and Technology, ETH Zürich, Winterthurerstrasse 190, Zurich, 8057, Switzerland.

Email: valerio.zerbi@hest.ethz.ch 
is processed by a shared set of brain regions, which are activated upon the sensorimotor transformation of socially encoded information (the "social brain") along with the tuning action of neuromodulators (O'Connell and Hofmann 2011, 2012). Despite increasing evidence, there is no consensus on a unified blueprint describing the brain systems that govern social behavior across species. Instead general confusion and disagreement still exists on which classes of social behavior can be generalized to other species and which are seemingly unique to humans (Kondrakiewicz and others 2018). Resolving these questions and thereby defining a common baseline for preclinical and clinical research promises a great advance in our understanding of social behavior and its regulation in health and disease.

In this review, we focus on social reward as a conceptual model of social behavior (Box 1). We first discuss its psychological and molecular basis as well as the extent to which these patterns are conserved across species. Drawing on recent studies, we present both correlational and causal evidence of network and circuital mechanisms that modulate social motivation in humans and in rodents. Finally, we aim to review the use of multimodal neuroimaging to understand socio-behavioral patterns on a network level and discuss this approach as a way to bridge preclinical findings with clinical findings in humans.

Box I. Social Reward as a Conceptual Model of Social Behavior.

\begin{abstract}
"Wanting": "Wanting" or mesolimbic incentive salience is a form of motivation that is largely generated by the mesolimbic dopamine system. It is typically less linked to cognitive goals but rather triggered in pulses by reward cues or imagery about the reward. The intensity of the triggered "wanting" urge depends for one on the current state of the individual's dopamine system and on the cue-reward association. This allows for state-dependent amplification of "wanting." Particularly in stressful states this process can increase vulnerability to relapse in addiction or related disorders.

“Liking": "Liking" comprises the actual pleasurable impact of reward consumption. Contrary to "wanting," "liking" does not depend on dopamine and is mediated by small hedonic hotspots scattered throughout the brain. These hedonic hotspots can amplify "liking" responses if neurochemically stimulated and form a hedonic circuitry that may be shared by diverse pleasures. Social Reward: Reward and its role for goal-directed behavior can generally be described in two dissociable psychological reward dimensions: "liking" and "wanting," both of which are applicable to social signals. The "liking" component refers to the hedonic value of said signals, that is, perceiving social stimuli as rewarding. Social reward is mediated via activity in the mesolimbic network and is generally thought to be conserved across species. Social rewards include group affiliation, emotional support, as well as social status and salient identity.

Social Motivation: A social stimulus that is "liked" is then typically "wanted." The "wanting" component refers to the incentive salience of the reward (i.e., social stimulus), which drives an incentive motivation to approach/seek and consume the reward. Social motivation constitutes an evolutionary adaptation to secure an individual's ability to function in a collaborative environment.

Social Behavior: Social behavior comprises a range of behavioral outputs mediated by social reward and social motivation including social orienting, social seeking, and social maintaining. Not only are social signals prioritized by attention (social orienting) but are typically the preferred stimulus to attend to as well (social seeking). In an attempt to engage/interact with others (social interaction) over an extended period of time, an individual develops maintaining strategies enabling him to establish and enhance interpersonal relationships (social maintaining).
\end{abstract}
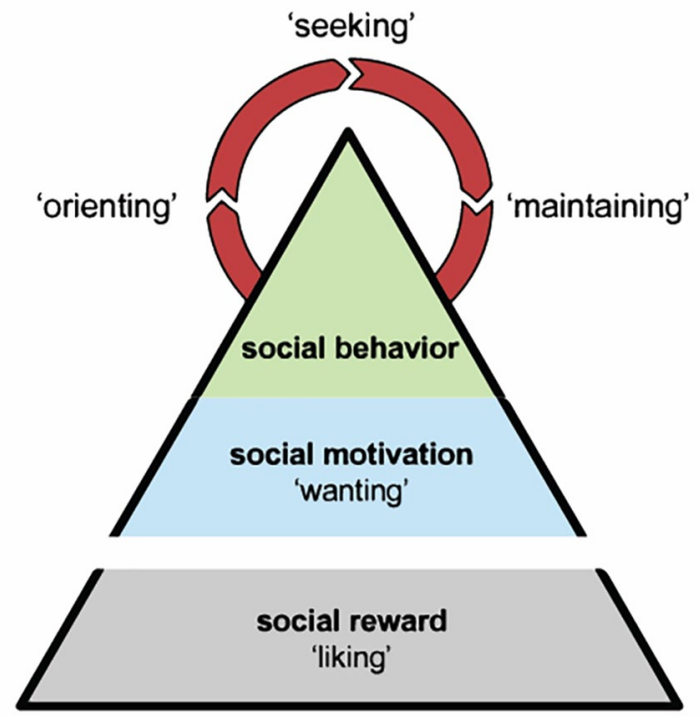


\section{What Is Social Reward?}

What makes a social stimulus rewarding and which mechanisms drive seeking this sensation time and time again? To understand the concept of reward and its role for goal-directed behavior, Berridge and others (2009) described two dissociable psychological reward dimensions: "liking" or the conscious experience of pleasure and "wanting" or the incentive motivation which promotes approach/consumption of rewards. Any type of reward that elicits "liking" is then typically "wanted." This general motivation system, which drives attention toward pleasant stimuli and avoidance of unpleasant/ stressful stimuli, varies in power and correlates with the individual's reward responsiveness and level of perceived reward value (Laricchiuta and Petrosini 2014). With regard to situations in which higher-order goals or social motives differ from initial desires (maybe undesirable ones even), dissecting reward-processes into "liking" and "wanting" proves particularly useful in explaining reward-orientation: drug seeking, binge eating, or sexual desire being just a few examples where liking is no longer a synonym of wanting (Finlayson and others 2011; Krishnamurti and Loewenstein 2012; Robinson and Berridge 1993). The described behaviors describe a state of "wanting" that is largely (and subconsciously) driven by the mesolimbic dopamine system. These may, however, conflict with the actual conscious goals and preferences of an individual, that is, "liking" (Mier and Kirsch 2017). In social psychology, prosocial behavior is assumed to have rewarding quality ("social reward") based on the display of a strong motivation to seek social relationships, support and understanding (Eisenberg and others 2010). Notably - but beyond the scope of this review-, social behavior might also be susceptive to states where "liking" no longer reflects "wanting" if we think of social media addiction or the upkeep of abusive relationships. During the past decade, the questions of where and importantly, how the brain encodes reward during social behavior have met extensive research efforts: data mostly from the field of cognitive neuroscience suggest the notion of a "social brain" where a network of brain regions displays specificity toward assigning reward values to social signals (Frith 2007).

\section{The "Social" Brain}

In humans, the medial prefrontal cortex (PFC), the temporoparietal junction (TPJ), subcortical structures, and the cerebellum can be considered social hub regions of the brain. Associated with social information processing, social cognition, and theory of mind, the functional interplay of these key nodes helps individuals adapt to and navigate the social world (Joiner and others 2017; Olsson and others 2020; Ruff and Fehr 2014; Wittmann and others 2018). Here we will focus on the key human brain regions linked to both reward and social processing.

Medial Prefrontal Cortex. The medial regions of the prefrontal cortex (mPFC) take on an important role in gating and mediating social behaviors within all levels of social cognition. The dorso-medial PFC (dmPFC), ventromedial PFC (vmPFC), and the anterior cingulate cortex (ACC) have been implicated in processes of social reward, punishment, and motivation (de Quervain and others 2004; Fehr and Camerer 2007; Kohls and others 2013).

The dmPFC has often been implicated in social processing, in particular "mentalizing" and theory of mind (Frith 1996) as well as integrating social information from other conspecifics (Martino and others 2017). Multiple studies showing increased activation of the dmPFC during joint attention tasks (shared focus of two or more individuals on an object/each other), as opposed to solo attention tasks (non-shared attention toward an object), have indicated that these regions are concerned with aspects of moral decision making and cooperative behavior (Amodio and Frith 2006; Redcay and others 2013). The vmPFC (including the subgenual anterior cingulate cortex [sgACC] and medial orbito-frontal cortex [OFC]) has repeatedly been associated with the encoding of self-referenced rewards, choosing between rewarding options and positive explicit evaluation of others (Dang and others 2019; Rushworth and others 2011). However, it has also been implicated in social motivation and reward: vmPFC damage due to stroke has been shown to result in social isolation, apathy and decreased prosocial behavior in human patients (Barrash and others 2000). Interestingly, another subregion of the $\mathrm{mPFC}$, the gyral surface of the anterior cingulate (ACCg), encodes reward-related information for other individuals (Apps and others 2012; Behrens and others 2008; Lockwood and others 2015). This way the ACCg compares the expected and actual outcome of another person's decision, referred to as social prediction errors (Apps and others 2013; Apps and others 2015; Balsters and others 2017; Hill and others 2016). The ACC, along with the orbitofrontal and vmPFC, are generally thought to mediate the rewarding nature of cooperation, which could drive social motivation (Luo 2018). Anatomically, subregions of the mPFC are densely interconnected and further connected with several other hub-regions of the "social brain," like the ventral striatum (VS)/nucleus accumbens (NAc), the ventral tegmental area (VTA), the amygdala, and cerebellum (Ghashghaei and others 2007; Kelly and Strick 2003; Middleton and Strick 2000; Passingham and others 2002; Schmahmann 1991). 
Temporoparietal Junction. The TPJ is considered a further key node within the 'social brain'. It comprises the supramarginal gyrus, caudal parts of the superior temporal gyrus and dorso-rostral parts of the occipital gyrus and integrates input from lateral and posterior thalamus, as well as auditory, visual, limbic, and somatosensory areas (Decety and Lamm 2007; Mars and others 2012). As part of the mentalizing system, neuroimaging studies have implicated the TPJ with social cognition and theory of mind (Hooker and others 2010; Mars and others 2012; Young and others 2010). Specifically, the right TPJ is associated with understanding others' mental states such as moral stances, thoughts, beliefs, and feelings (Frith and Frith 2006) and through its role in empathy processing, it may encourage prosocial behavior: Zanon and others (2014) investigated functional connectivity in brain networks of self-benefitting and altruistic participants during a life-threatening simulation. While the selfish individuals exhibited increased functional connectivity in the salience network, prosocial individuals presented with more integrated communication between the mPFC and the rTPJ. Interestingly, voxel-based morphometry (VBM) showed that gray matter volume in the rTPJ is strongly associated with an individual's level of altruism (Morishima and others 2012). Anodal transcranial direct current stimulation (tDCS) of the rTPJ for 20 minutes prior to a perspective-taking task enhanced the ability to take the visual perspective of another, though mentalizing ability was surprisingly unaffected (Santiesteban and others 2012). A 2018 study by Blair-West and others used active anodal tDCS to the rTPJ in a social decisionmaking task to potentially enhance prosocial decision making but failed to find a significant effect. Contrary to numerous neuroimaging studies demonstrating heightened rTPJ during social decision making (Guo and others 2014; Halko and others 2009; Rilling and others 2004; van den Bos and others 2014), this may reflect methodological considerations to using tDCS. Transcranial magnetic stimulation (TMS) of the rTPJ, on the contrary, successfully modulated mentalizing and sociocognitive processes in a number of studies (Bardi and others 2017; Baumgartner and others 2014; Hill and others 2017; Jeurissen and others 2014; Kelly and others 2014). Activation likelihood estimation (ALE) metaanalyses on VBM studies suggested that the posterior part of the rTPJ takes on an exclusive role in the social domain (Krall and others 2015). Complemented by metaanalytic connectivity mapping (MACM) and resting-state functional connectivity analysis, Krall and others (2015) found that the posterior rTPJ coactivates with typical ToM regions, while the anterior part shares connectivity patterns with the attentional network. Mars and others (2013) took the connectivity profile of the human TPJ to cortical areas and attempted to find relations to known homologues in the macaque temporal and parietal cortex. Their results suggested that macaque face processing areas and human mentalizing areas might share a similar evolutionary precursor.

\section{Subcortical Structures}

Basal ganglia. Electrophysiology and connectivity of the VS suggests that it encodes a variety of reward dimensions, including those of hedonic and motivational value (Daniel and Pollmann 2014). The feeling of being understood, receiving positive feedback or even the mere prospect of receiving positive feedback, the display of smiling faces as well as verbal praise all correlate with increased activity within the VS (Kirsch and others 2003; Rademacher and others 2010). With its central position in the mesolimbic pathway, the VS likely encodes the rewarding nature of cooperative behavior and thereby gates the motivational value of acting prosocially, that is, helping others (Bhanji and Delgado 2014). The NAc, prominently included in the VS, is also situated ideally to play a key role in processes of different reward dimensions, including those of a social nature (Meshi and others 2013). Spreckelmeyer and others (2009) reported activation of the NAc during the anticipation of positive social feedback, similar to anticipation of non-social outcomes like food (McClure and others 2007) or money (Knutson and others 2000). Kohls and others (2013) further implicated coordinated activity of NAc in the pursuit of social reward as well as the avoidance of social punishment. An investigation of cortico-striatal connectivity in a large sample of individuals with ASD $(\mathrm{N}=130$ per group) found there were significant differences in striatal connectivity patterns (Balsters and others 2018). Specifically, individuals with ASD did not show age-related changes in connectivity between the NAc and amygdala, or NAc and the frontal pole. In addition, the anterior and posterior sections of the putamen displayed unique connectivity patterns in typically developing individuals but not in ASD. This is particularly relevant in light of Pauli and others (2016) who suggested based on 5,809 human functional magnetic resonance imaging (fMRI) studies that activations in the anterior putamen are linked to social and language functions. Balsters and others (2018) suggest that the absence of unique connections to the anterior putamen could explain social and language deficits seen in ASD.

Ventral tegmental area. General acts without any direct beneficial outcome for oneself strengthen the assumption that pro-social behavior has an intrinsic motivational value: charitable behavior like donating and monetary pay-offs to charities activate the VTA 
comparable to monetary rewards to oneself (Moll and others 2006). Situated on the floor of the midbrain, the VTA harbors the majority of dopaminergic cell bodies of the mesolimbic pathway, which is strongly implicated in the natural as well as drug reward circuitry of the brain (Russo and Nestler 2013). Using a norm adaptation paradigm and an imaging approach tailored to detect activation within midbrain structures, Hétu and others (2017) suggested the substantia nigra (SN)/VTA complex and its dopamine system to be involved in social norm processing. Other human imaging studies found activation of the SN/VTA complex to reflect salience of a stimulus predicting reward and novelty seeking behavior, which could both be pharmacologically manipulated with dopaminergic agents (Menon and others 2007; Riba and others 2008).

Amygdala. In conjunction with the aforementioned areas of the $\mathrm{mPFC}$, amygdaloid activity is further central to handling the demands of complex social life. In fact, individual differences in amygdala volume predict variations in social network size and complexity (Bickart and others 2011). Based on its anatomical connections with almost every other brain region implicated in the "social brain" (as obtained from tract-tracing studies in non-human primates), it can be considered a hub within the "social brain" (Freese and Amaral 2009). Noninvasive functional neuroimaging studies have repeatedly indicated activation of the amygdala corresponds to complex social judgments (e.g., trustworthiness of another individual) (Winston and others 2002) and a variety of social signals (Morris and others 1996; Morris and others 1998). Adverse early-life experiences (e.g., motherly maltreatment) negatively affect the development of the amygdala and increase the risk of developing social impairments (Alink and others 2012; Lansford and others 2002; Ometto and others 2016), which typically precede adult-onset psychopathology (Mazza and others 2014). A recent study from Rausch and others (2018) showed significant differences in the connectivity-based parcellation of the amygdala in ASD, including reduced connectivity with the vmPFC.

Cerebellum. Despite being most appreciated for its role in sensorimotor control (Schmahmann 2004), ample evidence suggests cerebellar contribution in social behavior: functional neuroimaging studies find robust activation within the cerebellum associated with social cognition (Carta and others 2019; Moreno-Rius 2019; Van Overwalle and others 2015) and processing of primary emotions (Schmahmann and Caplan 2006). Overlaps between cerebellar activations for particular emotion categories (i.e., happiness, anger, disgust, fear, and sadness) imply the existence of shared neural networks across social and emotional dimensions (Baumann and Mattingley 2012). Lesions or resections can elicit cognitive impairment and abnormal social behavior (Schmahmann and Sherman 1998). Two key disorders of social cognition (ASD and schizophrenia) have been linked to cerebellar abnormalities (Andreasen and others 2008; Courchesne and others 1988; Wang and others 2014). Resting-state fMRI in patients with antisocial personality disorder (APD) revealed significantly reduced amplitude of low-frequency fluctuations in both the posterior cerebellar lobe (lobule Crus I) and OFC (Liu and others 2014).

\section{Do Rodents Have Homologous "social" Brain Circuits?}

Rodents like humans are socially engaged and show social behavior, though it presents in different forms. Depending on environmental contexts, rodents can display reciprocal interactions with conspecifics (Ben-Ami Bartal and others 2014), territorial aggression, mating via transmission, and interpretation of olfactory signatures (Rennie and others 2013), emotional contagion (Atsak and others 2011; Han and others 2019) and communication via ultrasonic signaling repertoires (Sangiamo and others 2020; see Chen and Wong 2018 for an extensive review). Therefore, rodent models are commonly used to investigate the neural correlates of both normal and abnormal social interaction. Preclinical research has already provided valuable insight into the cellular and neuromodulator mechanisms that fine-tune subregions of the "social brain." Using behavioral test paradigms, which selectively probe for different dimensions of social behavior such as emotional contagion or social and observational learning can then assess manifestation of the final behavioral output (Box 2). Recently, rapidly evolving cutting-edge neuromodulation technologies like opto- and pharmacogenetics (see Sternson and Roth 2014; Yizhar and others 2011 for extensive reviews) have enabled the manipulation of specific cellpopulations in a defined brain region, i.e. in a spatially and temporally controlled manner. These techniques allow for bottom-up research approaches, allowing us to go from cell to behavior, putting us in an ideal situation to investigate causality of brain-behavior interactions (see Fig. 1). Our understanding of complex behaviors, which are characterized by distinct internal states and switches thereof (Kaidanovich-Beilin and others 2011), can greatly improve using chemo- and optogenetic modulation. 
Box 2. Social Behavior Tests in Rodents.

Reciprocal Social Interaction Test: The test assesses direct social interaction in rodents. It can extract naturalistic social behavior phenotypes of the "resident" to an "intruder/stimulus" subject by direct contact. A "resident" subject is habituated to a new, cage-sized, and bedded arena before an unfamiliar "intruder" is introduced. Commonly observed social behaviors include nose-to-nose or oral-to-oral contact, sniffing, following, pushing over, crawling under, and potentially aggression. Manual scoring and/or tracking software can be used to identify and quantify these specific social behaviors. Notably, the test does not allow to distinguish between, e.g., lack of social motivation and impaired social cognition in rodent models, making translatability to human socially debilitating disorders difficult.

Three-Chamber Sociability and Social Novelty Task: The test assesses cognition as per general sociability and social novelty interest in rodent models of health and disease. Based on two inclinations, i.e., preference toward spending time with another rodent and social novelty preference, this test can help identify rodents with sociability/social novelty deficits. In three testing sessions, mice are placed into a three-chambered box with openings between chambers. After habituation to an empty box, the sociability session follows: the "resident" mouse encounters an "intruder" mouse placed under a transparent cup and an empty transparent cup in separate chambers. In the social novelty session, the "resident" mouse then encounters the familiar "intruder" mouse placed under a transparent cup and a novel "intruder" mouse also placed under a transparent cup. Out-read parameters for sociability and social novelty preference are time spent sniffing each transparent cup, time spent in each chamber and number of entries into each chamber. This way deficits in social behavior of disease models can be quantified and pharmacological agents can be tested for their effect on social behavior.

Social Conditioned Place Preference (sCPP): This test is a form of Pavlovian conditioning and can be used to measure motivational effects of social encounters/experiences. For the acquisition of sCPP, the conditioning procedure is carried out in an apparatus of two or more compartments. Both compartments can be discriminated by the subject via differently patterned/textured floors or walls. Testing comprises three stages: a habituation session on day one, training sessions on consecutive days and a SCPP test on the final day, all of the same session duration. During habituation the subject can freely explore all compartments to reduce novelty effects. A baseline preference toward either compartment is obtained by measuring and comparing the time spent in each compartment. For the conditioning sessions an unconditioned social stimulus (conspecific) is placed into one compartment. Throughout this phase the testing subject has access to this compartment only, which will result in association of this compartment with the social stimulus. During the sCPP test, the subject has unrestricted access to all compartments. As an out-read of preference, the time spent in both compartments is measured and compared with the baseline.

Ultrasonic Vocalization: Communication among rodents includes calls in the ultrasonic range. Shortly after birth pups start calling and elicit maternal licking, pup retrieval by the dam, and crouching behavior. Social communication under these terms can be measured by means of number, duration, frequency, and amplitude of calls. To investigate, e.g., pup communication, a single pup is placed into a Styrofoam chamber equipped with a microphone and recorded calls are analyzed with an appropriate program. The test can be repeated over the course of several days to record changes in communication. Rodents show a repertoire of ultrasonic vocalization which is increasingly as a readout of sociability given the caveats of behavioral social interaction tasks in general.

\section{The Rodent "Social" Brain}

Prefrontal Cortex. Most theories on the functions of key "social" brain areas have been derived from studies in humans and non-human primates. Therefore, true value of translatability between human and rodent research can only be ensured once similarities or homologues of key "social" brain areas have been defined. Arguably, the most intense debate has focused on translatability of functions of the prefrontal cortical areas across species. Although many behaviors attributed to the PFC are thought to be unique to humans, it is commonly accepted that rodents are still a valuable model for understanding the functions of frontal areas emerging before evolutionary separation (Carlén 2017; Laubach and others 2018; Wallis 2007, 2011). Cumulative evidence suggests that the infralimbic (IL) region in rodents and area 25 in nonhuman primates can be considered homologues (see Alexander and others 2019 for an extensive review; Heilbronner and others 2016; Vogt and Paxinos 2014).
Furthermore, prelimbic (PL) and cingulate areas $(\mathrm{Cg})$ are believed to be homologues of areas 32 and 24, respectively, in non-human primates (Aron and others 2004; Barbas and Pandya 1989; Bartra and others 2013; Bechara and others 2000). These homologies are further supported through lesion studies of the rodent PFC and its role in regulation of social reward processing. Findings of $\mathrm{Cg}$ involvement in social memory and interest as well as PL involvement in regulation of social investigation all point to the necessity of the rodent PFC in regulating social motivation (Avale and others 2011; Rudebeck and others 2007). Optogenetic manipulation of inhibitory parvalbumin (PV) interneurons and excitatory pyramidal neurons in the mouse PFC disrupted social motivation during the three-chamber task of social preference: Shifting the balance toward excitation resulted in reduced attendance of the social compartment, while no effect was observed once the excitatory/inhibitory (E/I) balance was shifted toward inhibition. Simultaneous activation of excitatory pyramidal neurons and inhibitory PV interneurons in the 


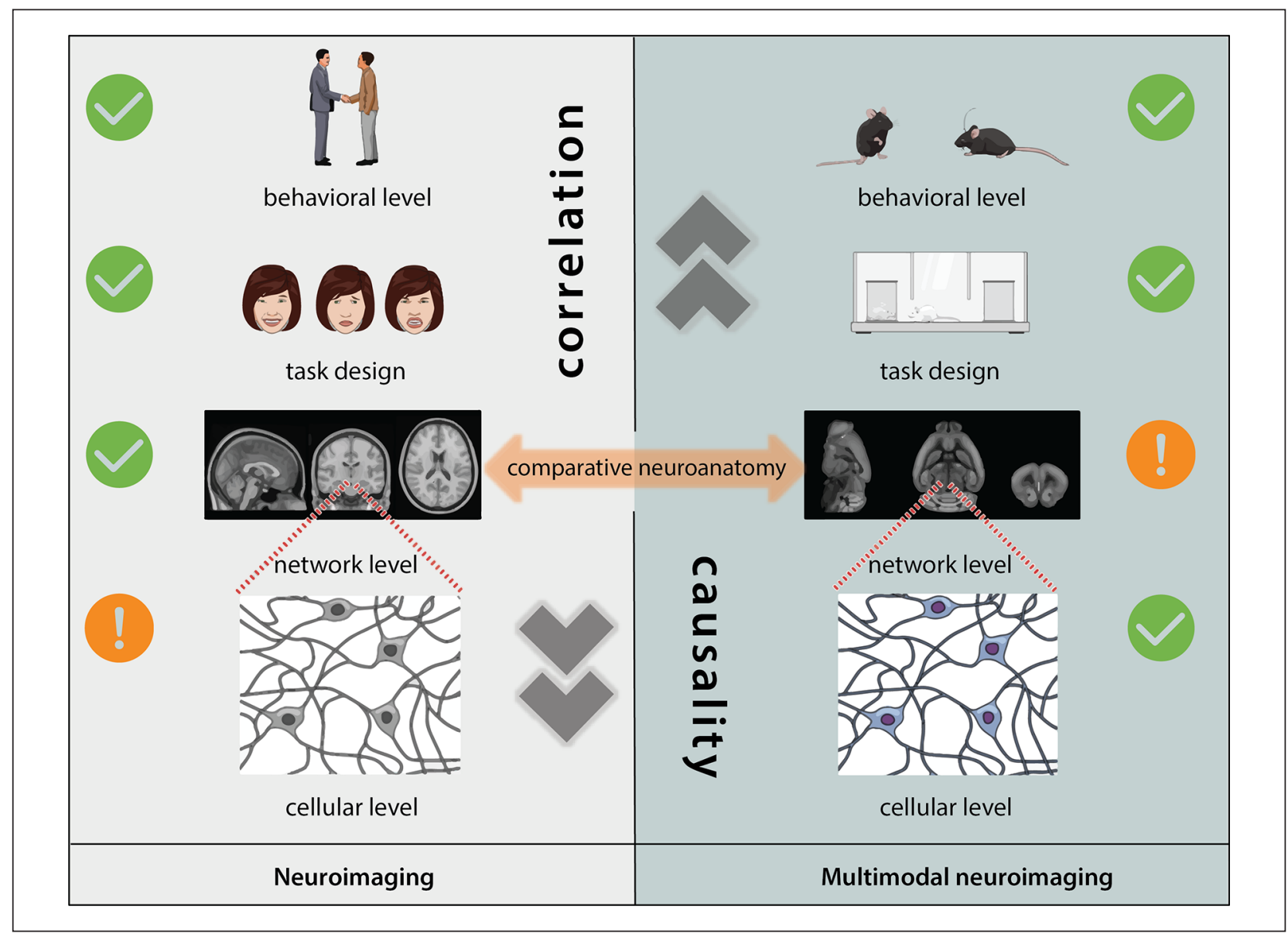

Figure I. Translational neuroimaging can bridge research of functional connectivity across species and levels of inquiry. Rodent models present an ideal system to test research hypotheses from bottom to top, that is, understanding neural processes from synapses to circuits to behavior. While efforts have been made to create a common ground for data acquisition (i.e., task design) and defining homologies in behavior, the shared biophysical principle of functional neuroimaging can ultimately provide insight to common and unique blueprints in brain activity patterns. With recent advances in rodent functional neuroimaging, the effect of different neural states is now accessible on a network level. The implementation of targeted manipulations (e.g., chemo-, optogenetics, genetic manipulation) further allows to causally explain changes in brain activity patterns, rather than correlational as in human research. This way, combining human and rodent neuroimaging research from top-to-bottom and bottom-to-top, respectively, we can systematically elucidate neurological underpinnings and their causal role within brain circuits of health and disease.

PFC, however, did not show an effect on social motivation in the three-chamber social task (Yizhar and others 2011). How PV interneurons in the dmPFC exert longterm impacts on social behavior has been elucidated via opto- and chemogenetic manipulation. Bicks and others (2020) discovered that brief optogenetic stimulation of dmPFC PV interneurons triggered active social approach to promote overall sociability. Chemogenetic activation of dmPFC PV interneurons, on the other hand, mitigated social deficits induced by juvenile isolation in adult mice. A recent study with multiplexed DREADD experiments bidirectionally modulated PFC activity to measure the effects on a behavioral and functional level (Benekareddy and others 2018): PFC hyperactivity suppressed the preference of social contact in a three-chamber social task and modulated activity in a subset of regions associated with emotional behavior. Bidirectional PFC modulation further identified the lateral habenula to receive direct prefrontal inputs which upon activation or inhibition suppress or promote social preference, respectively. Other studies found that the behavioral capacities related to social reward motivation and self-reward value assignment that have been attributed specifically to the human ventromedial prefrontal cortex (vmPFC), are localized to the rodent prelimbic (PL) and infralimbic (IL) areas (Bicks and others 2015). Anatomically, tracer studies show dense interconnections among subregions of the rodent $\mathrm{mPFC}$, along with projections to the VS/NAc, the 
VTA, and the amygdala (Gross and Canteras 2012; Vazdarjanova and others 2001). Human data have consistently implicated the ACCg in reward motivation of others (Apps and others 2016) and linking social agents to particular stimuli (Lockwood and others 2018). In rodents a potentially homologous area has been located in the ACC: Electrophysiological recordings in the ACC $\mathrm{Cg} 1 / \mathrm{Cg} 2$ region of freely moving rats revealed that a large proportion of neurons coded the net-value of competing for a reward as long as competition with a conspecific was required (Hillman and Bilkey 2012). Lesioning of these subregions resulted in disruption of both costbenefit decision making (Rudebeck and others 2006) as well as taking interest in other rats (Rudebeck and others 2007). This would suggest sub-regions of the ACC to be particularly important in learning about the behaviour of conspecifics and the cost-benefit information about an animal's own behavior (Apps and others 2016).

Subcortical Structures. Similar to humans, the contribution of reward mediating subcortical areas like the VS/ NAc and the VTA further strengthen prosocial functioning in rodents (Gunaydin and others 2014; Kas and others 2014).

Ventral striatum. The rodent striatum, similar to the human striatum, is held as a general-purpose subcortical region which can translate social information into measures of social action and reward (Bariselli and others 2016). In particular, the VS shows specific involvement at the social level: Social isolation experiments in rats produced a "hypersensitive" VS, where events that would naturally trigger dopamine release resulted in an exaggerated effect possibly through increased expression levels of dopamine D2 receptors within the VS (Hall and others 1999; Howes and others 2000). Additionally, as part of the VS, NAc activity also proved to be relevant in processing of social reward (Walsh and others 2018) and in facilitating social behaviors (Kohls and others 2013).

Ventral tegmental area. Increased activity within the VTA was found to be necessary to promote social exploration (Gunaydin and others 2014). Mouse models with deficits in postnatal development of excitatory transmission onto VTA neurons display sociability deficits later on, which could be restored upon early administration of a pharmacologic modulator postnatally (Bariselli and others 2016). Lang and others (2019) examined male prairie voles' brain response to infant-related odors and found female cues (i.e., female cohabitation) to enhance fos activity in the VTA on exposure to infant cues.

Amygdala. Besides its role in fearful behaviors, lesion studies have causally linked the amygdala to social deficits (Daenen and others 2003). Optogenetic manipulation of direct BLA-mPFC projections could bidirectionally modulate social behavior and produce/mitigate anxiogenic effects (Felix-Ortiz and Tye 2014) Exploration of resting-state fMRI data of an early-life stress mouse model focused on fronto-limbic connectivity compared with a control group and found amygdala-PFC hyperconnectivity, which highly correlated with anxietylike behavior (Johnson and others 2018).

Cerebellum. Similar to the evolving trend in human research, cerebellar function has recently been put into context with social behavior in rodents as well. Carta and others (2019) demonstrated a direct regulatory role of monosynaptic connections onto VTA activity and thereby could regulate decision-making and emotional control: Optogenetic activation of the cerebello-VTA projections powerfully activated the reward circuitry. The authors additionally found increased activity of these projections upon exploration of conspecifics. Chemogenetic inhibition of Purkinje neurons (PN) within the Right Crus I (RCrusI) region of the cerebellum produced robust ASDrelated social, repetitive and restricted behaviors (Stoodely and others 2017). Stimulation of these neurons in a genetic mouse model of ASD rescued its social impairments, warranting the therapeutic potential of cerebellar neuromodulation in ASD. Furthermore, chemogenetic perturbation of Crus I/II molecular layer interneurons in juvenile mice produced altered social preference throughout adult life (Badura and others 2018).

Overall, cumulative evidence points to a conserved set of brain regions involved in processing of and assigning value to social information in rodent and human (see Fig. 2, Table 1; see Prounis and Ophir 2020 for a critical view on the social brain). These homologies set a first basis for translational research on social behavior in health and disease. However, social interaction involves cognitive and emotional processes that may not be "social" per se, which makes it difficult to control for during experiments. Ensuring adequate assessment of attention during short-term habituation, reward and saliency processing and appropriate levels of anxiety versus exploratory drive are just a few of the measures that must be taken to reduce false-positive reports on sociability. Nevertheless, by making use of our ability to target specific cell-populations in rodents, we are able to add another layer of complexity through the determination of their dedicated role in complex behaviors.

\section{Comparable Neurotransmitters to Regulate Social Reward Value}

Neuromodulators primarily act on slow acting receptors through which they regulate diverse neuronal populations 


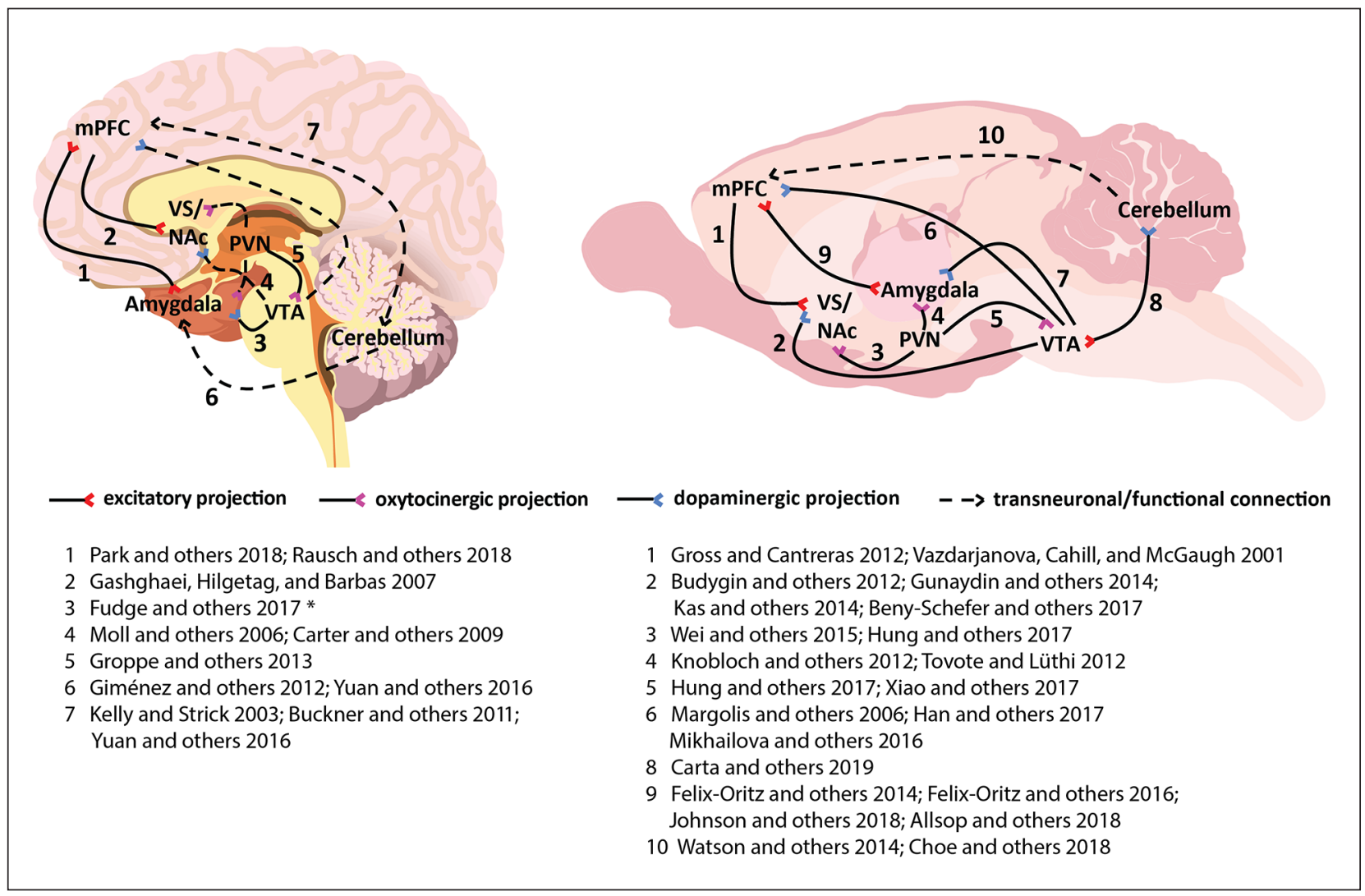

Figure 2. Comparable social actuators in the human and rodent brain. Indicated here in sagittal are areas comprising the social brain and their interconnections as described in human and rodent research (numerical index). Human neuroimaging and rodent research using neuromodulation and electrophysiology has established relationships between various social behaviors and activity in specific neural circuits. Furthermore, the critical role of neurotransmitters and hormones like dopamine (indicated in blue) and oxytocin (indicated in purple) in gating/tuning social behavior within these circuits have been subject of investigation. While social hubs such as the VTA, VS/NAc, PVN, and amygdala have been established in both human and rodent, the role of the mPFC or the cerebellum are less defined. Notably, detailed circuit connectivities (dashed lines) and directionality of connections are still to be characterized with help of rodent models across different levels of inquiry. mPFC, medial prefrontal cortex; VS, ventral striatum; NAc, nucelus accumbens; PVN, paraventricular nucleus; VTA, ventral tegmental area. *Non-human primate tracer studies.

and modulate their response patterns to specific stimuli. In a social context, dopamine (DA) and oxytocin (OT) are repeatedly reported to be involved in information processing and behavioral output in both rodents and humans (see Goodson 2013). In the mammalian brain, two adjacent midbrain regions, the VTA and substantia nigra pars compacta $(\mathrm{SNc})$, comprise the majority of DA neurons. VTA-DA neurons are well known to project broadly throughout the brain, including the mPFC, NAc, and amygdala (Brischoux and others 2009; Budygin and others 2012; Chaudhury and others 2013; Lammel and others 2008). Early studies implicated strong phasic activity of DA neurons ("dopamine transients") as a response to reward stimuli in rodents (Berridge and Robinson 1998; Schultz and others 1997). In vivo neurochemical methods revealed that phasic dopamine signals in the VS, possibly influenced by midbrain, amygdaloid and vmPFC inputs, correlated with reward-seeking behaviors (Robinson and others 2011). Optogenetic phasic activation of mouse VTA-DA neurons was found to drive behavioral conditioning in a conditioned place preference task (Tsai and others 2009). Moreover, on phasic firing, DA terminals in the NAc appear to corelease glutamate, thereby activating fast ligand-gated ion channels and allowing transients to be truly time-locked to stimuli and reward (Stuber and others 2010; Tecuapetla and others 2010). While tracking subsecond DA fluctuations is not possible in humans, with recent studies implementing adaptations of fastscan cyclic voltammetry (FSCV) to measure neurotransmitter changes in deep-brain structures (Kishida and others 2016; Kishida and others 2011), phasic DA signals are now commonly described as encoding of reward signals or the motivational component of reward ("wanting”) (Berridge and Robinson 2003). Genetic and 


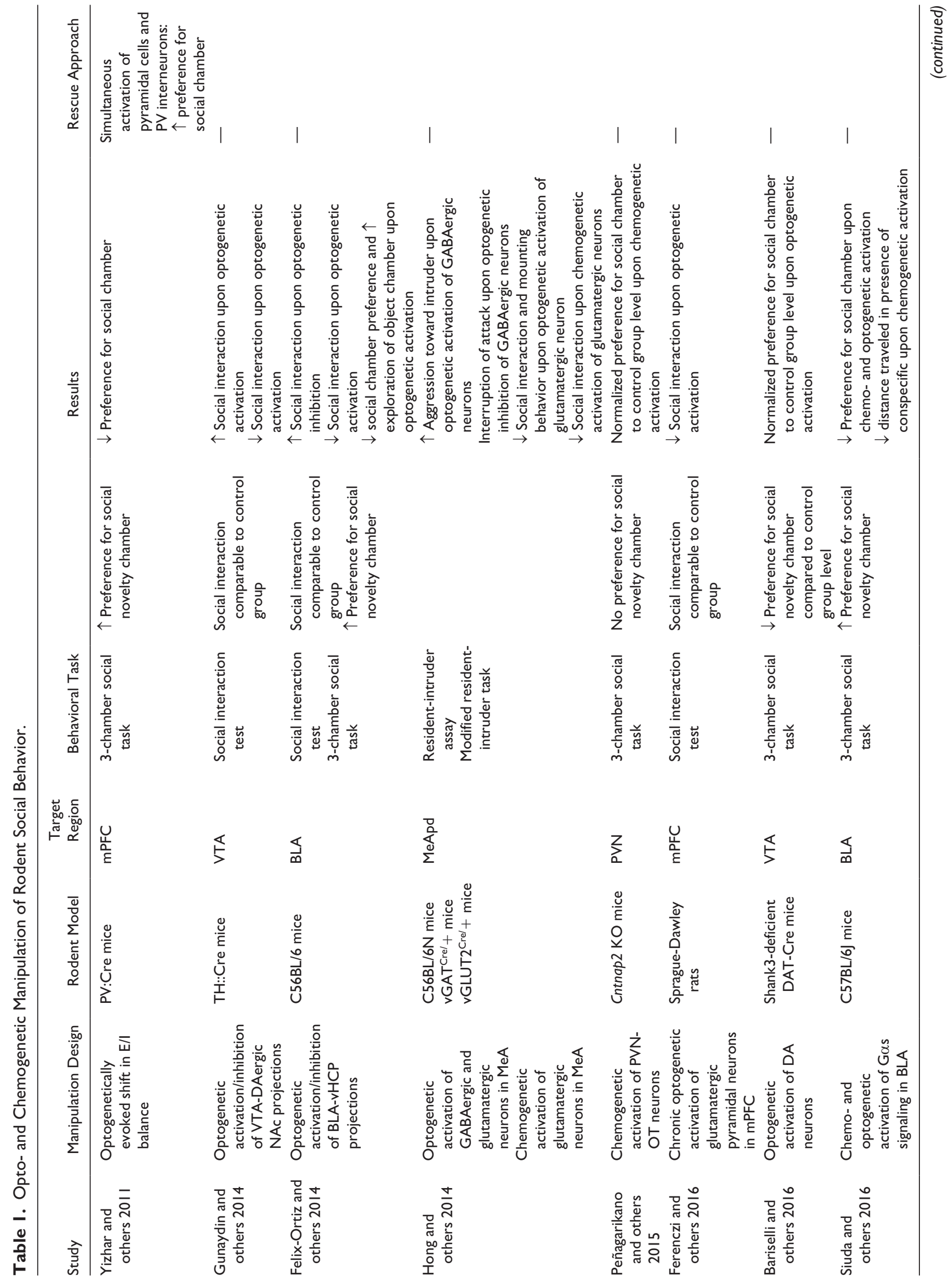




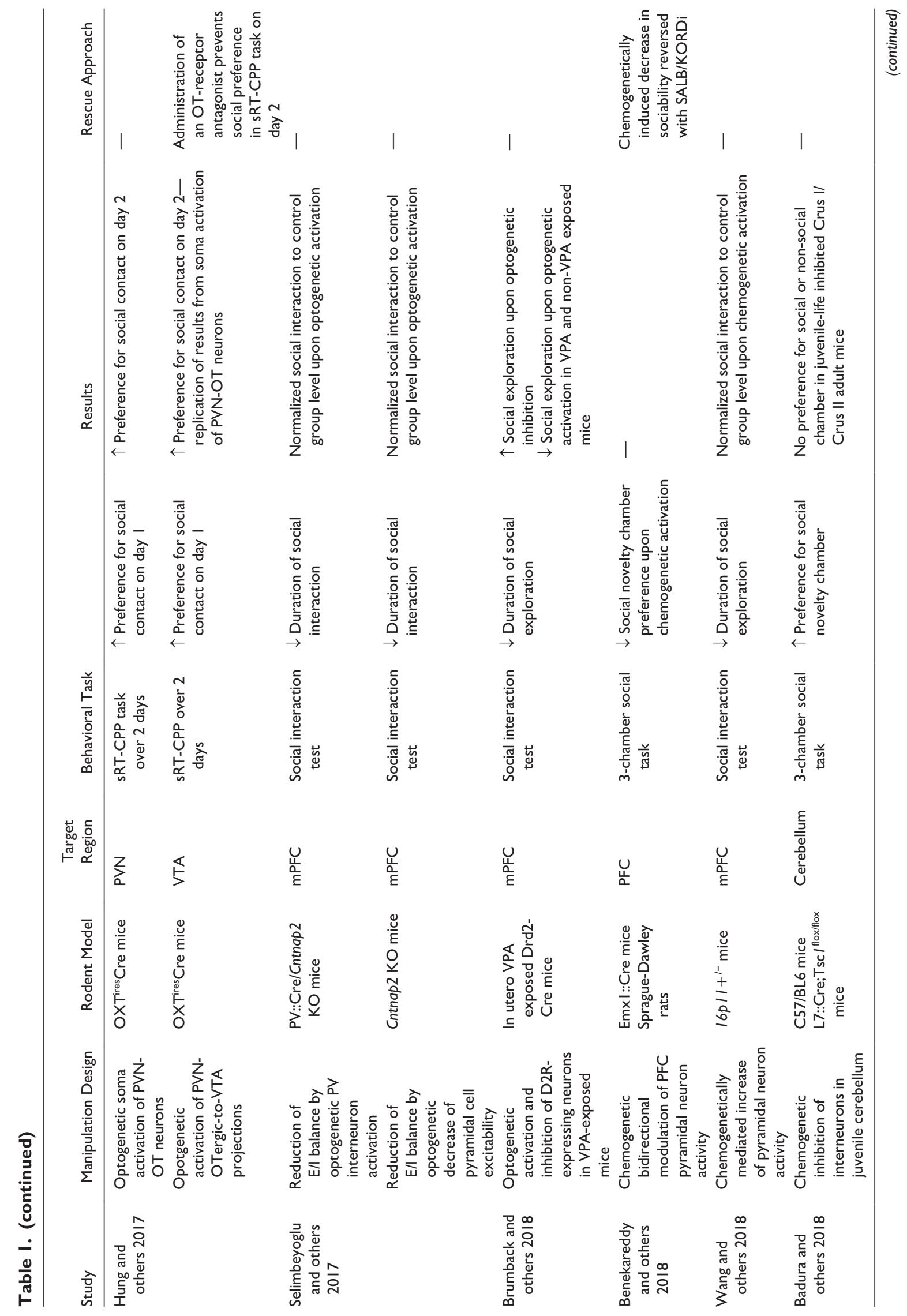




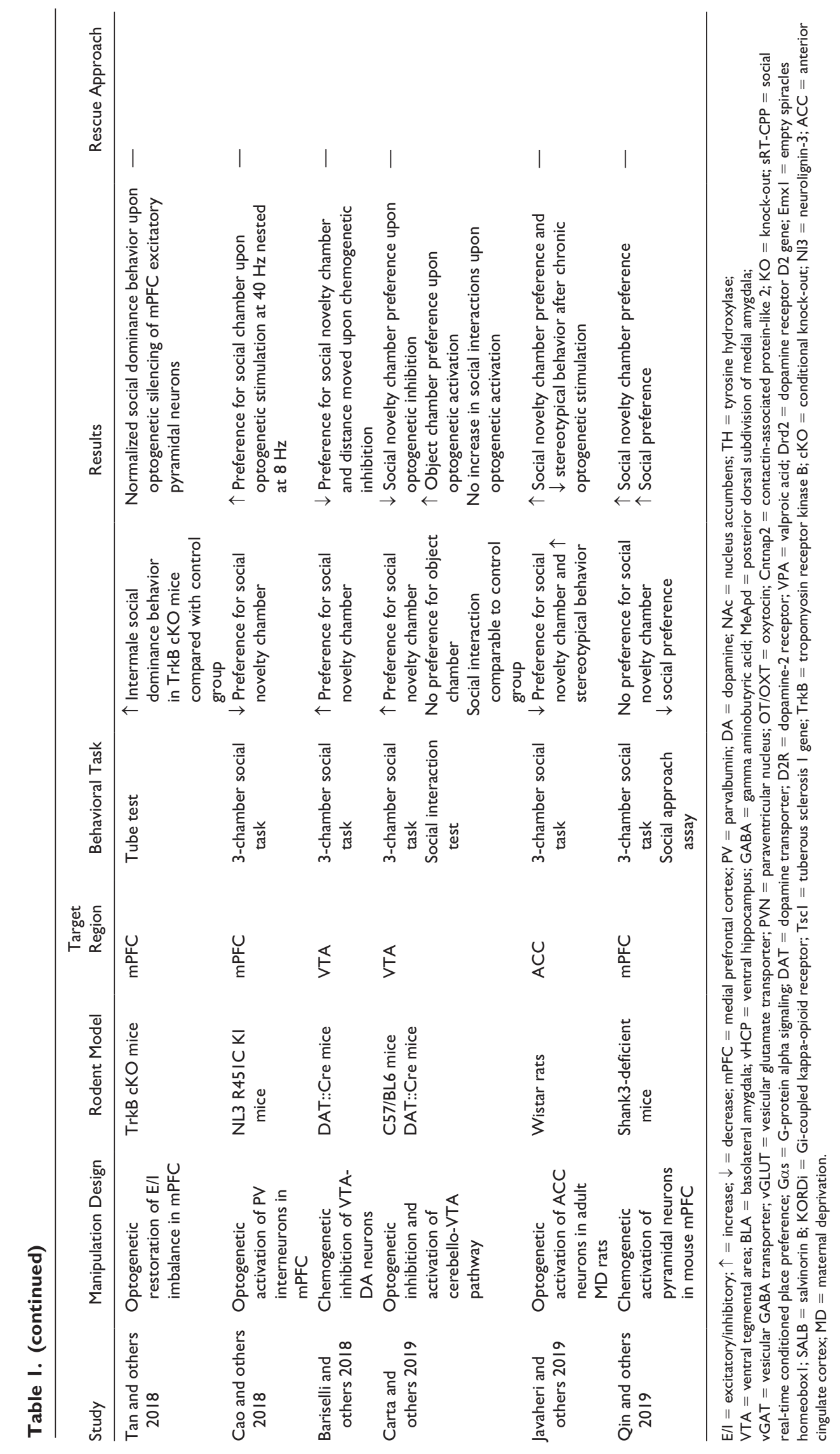


pharmacological studies in both humans and rodents have also proven a critical role of the DA system in social interaction: human carriers of the nine-repeat allele of DAT1, a DA transporter, were reported to show stronger social approach tendency, while increase of DA concentration through a pharmacological agent improved learning about pro-social preferences of a partner (Eisenegger and others 2013; Noritake and others 2018). Additionally, human gender differences in social preferences were recently attributed for the dopaminergic reward system: pharmacological reduction of receptor-type specific actions of dopamine resulted in more selfish decisions during an interpersonal decision task in women while male participants exhibited an increase in prosocial decisions (Soutschek and others 2017). In rodents, FSCV measurements demonstrated increased DA transient frequency throughout the dorsal and ventral striatum on investigation of a novel conspecific (Robinson and others 2002). More targeted recordings from the NAc revealed DA release when animals were orienting toward and experienced initial contact with the conspecific, which would cease or rather habituate on subsequent contact (Robinson and others 2011). Despite accumulating evidence of DA's critical role in the brain's reward circuitry, a central question remains: what mechanism is tuning or rather gating VTA-DA neuron activity during social behavior? A first insight into the natural and causal circuit dynamics which underlie the modulation of social behavior was given by Gunaydin and others (2014), who found that the dynamics of VTA to NAc projections are both encoding and predictive of social interaction in mice. This finding was supported by evidence that VTA-DA neurons are implicated in the mediation of motivated behavior via a top-down reinforcing circuit from the anterior cortex, including the $\mathrm{mPFC}$ and orbitofrontal cortex, to lateral NAc (Beier and others 2015). Given the diversity of connectivity patterns and the large number of downstream VTA targets, understanding what is happening upstream of VTA-DA neurons might help pinpoint connectivity patterns that contribute to modulation of reward and aversion.

Besides DA, the neuropeptide OT, which is synthesized in the paraventricular nucleus (PVN) and supraoptic nucleus of the hypothalamus, has been often associated with social motivation in both humans and rodents (Lukas and others 2011). Initially proclaimed as a hormone strongly affected in social bonding, OT is now known to play a key role in several dimensions of social functioning, including fear responses, emotional memory, and social reward processing (Hu and others 2015; Knobloch and others 2012; Marlin and Froemke 2017). OT reportedly modulates $\mathrm{E} / \mathrm{I}$ balance in the auditory cortex of female mice in response to pup calls and thereby enables pup retrieval behavior (Marlin and others 2015). The neuropeptide also showed critical involvement in the development of all sensory cortices upon early sensory experience (Zheng and others 2014). In vivo OT injection together with increased sensory experience rescued effects of sensory deprivation by elevating excitatory synaptic transmission. Furthermore, OT receptor-expressing somatostatin (SST) interneurons within the mPFC show a differential response to OT in male vs female mice: in female mice these OT receptor (OTR) expressing neurons drive motivation to interact with male mice during estrus, while no changes in motivation were observed toward other females (Nakajima and others 2014). DREADDdriven excitation of OTergic neurons in the PVN of a mouse model of ASD was able to rescue social behavior in the 3-chamber task as assessed with normalized social interest (Peñagarikano and others 2015). Wei and others (2015) further reported these neurons to convey information about the rewarding properties of social interaction via cannabinoid-mediated signaling in the NAc (Wei and others 2015).

Since DA receptors are present on OT neurons and OT receptors can be detected in the VTA and $\mathrm{SNc}$, a reciprocal modulation of both neuromodulator systems seems apparent (Baskerville and Douglas 2010; Grinevich and Stoop 2018). Consequently, the precise DAergic circuits which are involved in OT-sensitive behaviors should be questioned: How do DAergic and OTergic outputs guide social interactions? A recent study in mice reported a mechanistic link between VTA-projecting OT neuron activity in the PVN and social reward: OT release in the VTA enhanced the activity of reward-specific DA neurons, which could possibly correlate with the reinforcing component of social interactions via increased DA release in the NAc (Hung and others 2017). Ex vivo electrophysiological recordings of mouse VTA-DA neurons further showed the diverse functions of OT, whereby it could enhance the salience of partner-directed versus exploratory behavior by increasing DA neuron activity in the VTA but downregulating it in the substantia nigra pars compacta (SNc) (Xiao and others 2017). Indeed, while VTA-DA neuron activity might enhance social interest, DA neuron activity in the SNc could presumably dampen contextually irrelevant exploratory behavior via controlling motor activity (Gunaydin and others 2014; Patel and others 2012). OT release in the VTA and SNc might therefore be a crucial factor in estimation and modulation of the salience of a social encounter or possible prosocial behaviors.

While in rodent studies evidence of OTergic modulation of social reward processing accumulates, its role in human social behavior is less definite. Imaging studies report that upon social stimuli OT preferentially enhances connectivity of the brain's reward processing system (Gordon and others 2016). Similar to animal literature, 
Groppe and others (2013) described the VTA as the brain region where OT modulates the salience to socially relevant cues via mesolimbic dopamine projections. More specifically, they observed intranasal OT application to increase the VTA BOLD (blood oxygen level dependent) response to socially rewarding and punishing cues in a social incentive delay fMRI task. OT was also reported to facilitate learning by giving feedback of both socially rewarding and punishing modalities (Gregory and others 2015). Liu and others (2019) found intranasal OT application to amplify social value representations within the amygdala (i.e., value of one's own interest relative to interest of others), resulting in more prosocial behavior in more individualistic rather than social subjects. Quintana and others (2017) characterized the distribution of three genes involved in the OT signaling pathway across the brain and assessed associations between gene expression patterns and mental states via large-scale fMRI metaanalysis. The expression maps of OXT (structural gene for oxytocin), OTR, and CD38 (central oxytocin secretion) showed an increase in central, temporal, and olfactory regions, which corresponded with motivation and emotion processing. Given its relevance in prosocial engagement, research on OT's regulatory processes in disorders of social dysfunction like ASDs has gotten more and more attention. However, only few clinical studies have directly linked autism-like phenotype to problems in OT signaling: While clinical application of intranasal OT at a single dose promoted prosocial behavior in high-functioning autism patients (Aoki and others 2014; Anagnostou and others 2012; Andari and others 2010), further doses of the agent failed to replicate these effects (Guastella and others 2015). At first glance, OT might appear to be just the missing agent to successful pharmacological treatment, however, consistent and reproducible data regarding its effects on regulation of social behavior are still missing (Miller 2013).

The sum of preclinical and clinical studies on the "social brain" and its neurotransmitter systems (see Fig. 2) have given great insights as to what is contributing to sociability, the value we assign to social interaction which ultimately motivates us to seek out social contact. Still, work on social reward in rodents has mostly focused on deciphering its molecular and neural basis and how it translates to behavior, while human research is limited to set the behavioral phenotype as a basis and investigate it on a network level. From a translational perspective the key macroscopic difference here becomes clear: in all these years of research we have yet to establish a "common language" between human and rodent studies, both in terms of neuroanatomy and behavior. Including the network-level characterization of circuit- and cell-specific stimulation in rodent models, that is, combining optogenetic of chemogenetic with the same neuroimaging readouts as in human studies might just be that connective which enables us to translate findings from rodent to human research, and vice versa.

\section{Translational Neuroimaging: Bridging the Gap}

Multimodal approaches that include optogenetics and/or chemogenetics with fMRI could provide the interface to enable proper communication between clinical and preclinical research (Fig. 3). Today, optogenetics and chemogenetics allow the manipulation of virtually any chosen brain area or pathway and can model the neural dynamics observed in awake animals during a particular behavioral paradigm (Christie and others 2017; Lee 2012; Lee and others 2010; Rungta and others 2017). Measuring the whole-brain fMRI responses allows to parameterize the causal relationships between a specific input and the response of a distributed network of brain areas (BernalCasas and others 2017), including those of downstream connected circuits (Lee 2012), and overcomes the need to design a task-paradigm during the scan. These define the opto-fMRI as a powerful tool suitable for testing the circuit hypothesis within the framework of social reward and social motivation in rodents, describe their effects at the network level, and used to explain the data from human literature. For example, Ferenczi and others (2016) were the first to demonstrate the utility of optofMRI for testing a systemic hypothesis on reward processing - adapted from human imaging data - and found the rat $\mathrm{mPFC}$ to exert top-down control over interactions among subcortical striatal regions which govern general reward-related responses (Ferenczi and others 2016). Lohani and others (2017) next embarked on VTA-DA neuron activation in rats and showed how this influences regional and global fMRI signals. Specifically, they found that phasic activation increased BOLD and cerebral blood volume (CBV)-weighted fMRI signals in limbic regions innervated by the VTA, such as the NAc. It came as a surprise, however, that sparsely VTA-DAergic innervated regions of the basal ganglia (dorsal striatum, globus pallidus) also showed activation. Indeed, the most prominent fMRI signal increase came from the dorsal striatum, a region generally not associated with VTA-DA neurotransmission, which suggested a functional connection of meso- and non-limbic basal ganglia DA circuits (Lohani and others 2017).

\section{Rodent and Human Circuit Homologues?}

Given the similarity of activated networks to what is reported from human fMRI data, neuroimaging can be credited as a powerful translational tool that can be applied to examine homologies and differences between 

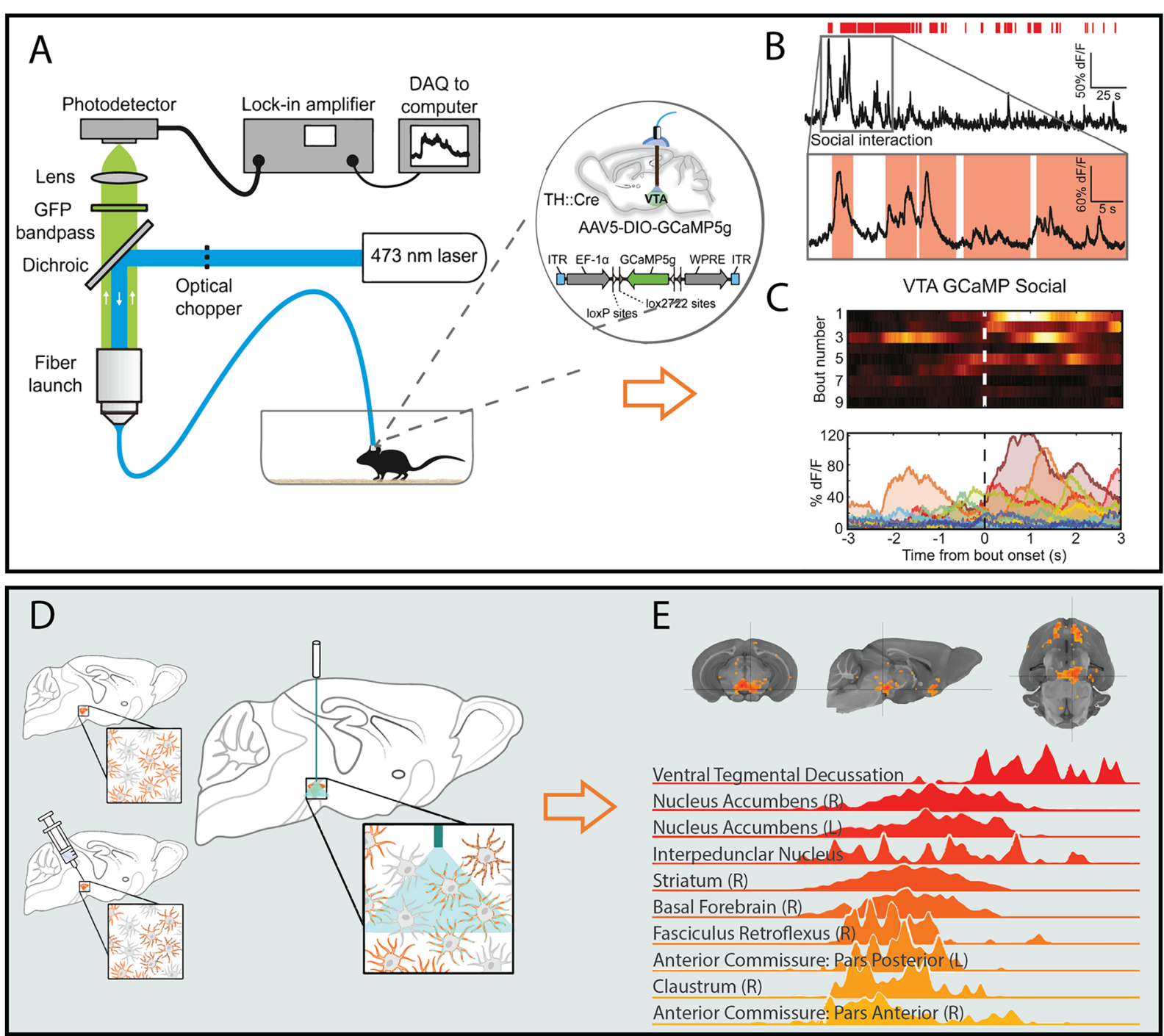

Figure 3. Multimodal measurement of neural dynamics in rodents. (A) Cutting-edge optical imaging techniques have enabled the detection of real-time activity of specified neural projections in socially interacting animals. A photometry setup enables optogenetic excitation and/or fluorescence emission recordings of targeted neuron through a single $400 \mu \mathrm{m}$ fiber-optic implanted in ventral tegmental area (VTA). (Right) Viral targeting of GCaMP5 to VTA-DA neurons. (B) Photometry traces from mice expressing GCaMP5g in VTA during social behavior. (Red dashes) Interaction bouts. (Bottom) Zoom-in of gray box from above relating VTA-DA GCaMP signal and social interaction (colored boxes). (C) Example heatmaps (top) and peri-event plots (bottom) aligned to start of interaction for mice expressing GCaMP (left). (Heatmaps) Warmer colors indicate higher fluorescence signal; (peri-event plots) warmer colors represent earlier interaction bouts. (D) The combination of targeted neuronal modulation (e.g., chemogenetics, optogenetics) with fMRI brain-wide readout allows researchers to investigate the effects of acute neuromodulation not only in the targeted region(s) but also in downstream connected circuits; this may overcome a current limitation of single-cell and electrophysiological recordings, which assume a direct relationship between the manipulated brain area and behavioral changes. This approach proves to be particularly valuable in understanding how complex behaviors arise from cellular processes to connectional changes to inter-regional activity changes at the whole-brain level. Selective targeting of dopaminergic neuron is achieved using AAV5-DIO-channelrhodopsin2 viral delivery in the VTA of DAT-Cre mice. (E) General linear modeling (GLM) of stimulus-evoked activity followed by a mass univariate regression analysis produced voxelwise spatially resolved opto-fMRI activation maps. Representative distribution densities of statistic values from blockstimulus-evoked activity analysis. Depicted are the 10 most strongly activated areas. Figures adapted from Gunaydin and others 2014; Horea and others 2020 (in revision) with permission. 
species. But which are the brain networks that have been maintained through evolution in humans and rodents? Are reward and social motivation circuits among them? An answer to these outstanding questions is given by comparative functional neuroanatomy, a branch of neuroscience that studies the organizational level of the central nervous systems from an evolutionary perspective and aims to identify which functions of the brain are conserved or unique across species. However, only recent attempts have been made to study similarities and differences between rodents and primates in their neuroanatomy as well as in the physiology of their brain networks. In 2014, Stafford and colleagues used functional brain imaging to compare the topology of the "default mode network" (DMN) - a set of regions that have been linked to social cognition and understanding of others (Laird and others 2011; Li and others 2014; Mars and others 2012) - in mice and humans in detail (Stafford and others 2014). Their results show striking similarities in the way DMN is connected to the anterior cingular, retrosplenial, orbitofrontal, and parietal cortex. However, prefrontal components such as the posterior cingulate cortex (likely area 23) do not have a clear correlate in the mouse. In our recent study, we compared cortico-striatal connectivity profiles in mice, macaques, and humans with resting fMRI (Balsters and others 2019). These results suggest that connectivity models for both the nucleus accumbens - a hub for reward processing - and the cortico-striatal motor circles (posterior/lateral putamen) have been preserved, making them reliable targets for comparing species. However, a large area of human $(85 \%)$ and macaques $(69 \%)$ striatum does not have a clear mouse homolog. These areas were located in the caudate nucleus and anterior putamen, overlapping the executive function and the social / linguistic regions of the striatum, and connected to prefrontal-projecting cerebellar lobules and anterior prefrontal cortex, forming circuits that seem to be unique for non-human primates and humans. We attributed these differences to the expansion of the frontal cortex and parietal frontal lobes in humans. Taken together, these studies suggest that functional systems that relates to social cognition can be seen in mice, but they are often not present to the fullest extent as observed in primates. Further studies need to be carried out to refine the existence of similarities and differences between species in cycles that are relevant to specific aspects of behavior, including social behavior. We propose that this information is essential for assessing the human translation potential of circuit manipulation studies in rodents. Only if good agreement is observed can we guarantee that a particular process or behavior emerges from the same circuit, and therefore the theories developed in human studies can actually be used for rodent research—and vice versa.

\section{Future Directions}

The preclinical application of fMRI in combination with specific neural stimulation techniques is a foreseeable strategy for modeling, examining, and comparing the network signatures of human behavior, including those that are related to reward processing and its manifestation in social behavior. This has the potential to answer fundamental questions about the origin and physiological meaning of social behavior by integrating targeted and causally explainable manipulations of specific neurobiological pathways into the same fMRI design scheme as human studies. For example, it allows to assess whether the activation (or deactivation) of a particular structure, pathway, or modulatory system gives rise to similar network-level changes between rodents and humans. This overcomes the need to evaluate the similarity of results using complex and often not comparable behavioral assays. These observations form the basis of a new branch of neurosciencecomparative functional neuroanatomy-and provide insights into the neural mechanism that are evolutionary preserved (or not) between species. As this is an emerging research field in its infancy, there are many unknowns that need to be addressed, starting from mechanistic insights linking fMRI biomarkers to neural signaling. With careful interpretation of obtained results, comparative functional neuroanatomy may greatly advance translatability of preclinical studies in rodents toward humans.

\section{Conclusion}

Understanding the neural mechanisms conveying social functioning is key for the development of effective therapeutic interventions in socially debilitating disorders. Despite intensive research in a healthy and diseased state, it remains of question whether the observed activity patterns are causative or a by-product of information processing. As a complement to human studies, rodent studies can provide just that: Specific gene mutations can be created, molecular pathways can be targeted, and microcircuits can be manipulated, all while the observed effects can be causally explained. Using neuroimaging as an objective method of data readout and analysis is proving promising in understanding the brain functional basis of sociability as well as for monitoring the effectiveness of therapeutic interventions. Furthermore, these studies offer the possibility of studying network-level analogies between multiple species, filling the vital need to harmonize the results on the mechanisms of the social brain measured in rodents with the theories on the functioning of the social brain established in humans.

\section{Declaration of Conflicting Interests}

The author(s) declared no potential conflicts of interest with respect to the research, authorship, and/or publication of this article. 


\section{Funding}

The author(s) disclosed receipt of the following financial support for the research, authorship, and/or publication of this article: $\mathrm{CG}$ and $\mathrm{VZ}$ are supported by the SNSF AMBIZIONE PZ00P3_173984/1.

\section{ORCID iD}

Valerio Zerbi (iD https://orcid.org/0000-0001-7984-9565

\section{References}

Alexander L, Clarke HF, Roberts AC. 2019. A focus on the functions of area 25. Brain Sci 9(6):129. https://doi. org/10.3390/brainsci9060129.

Alink LRA, Cicchetti D, Kim J, Rogosch FA. 2012. Longitudinal associations among child maltreatment, social functioning, and cortisol regulation. Dev Psychol 48(1):224-36. https:// doi.org/10.1037/a0024892.

Allsop SA, Wichmann R, Mills F, Burgos-Robles A, Chang CJ, Felix-Ortiz AC, and others. 2018. Corticoamygdala transfer of socially derived information gates observational learning. Cell 173(6):1329-42.e18. https://doi.org/10.1016/j. cell.2018.04.004.

Amodio DM, Frith CD. 2006. Meeting of minds: the medial frontal cortex and social cognition. Nat Rev Neurosci 7(4):268-77. https://doi.org/10.1038/nrn1884.

Anagnostou E, Soorya L, Chaplin W, Bartz J, Halpern D, Wasserman S, and others. 2012. Intranasal oxytocin versus placebo in the treatment of adults with autism spectrum disorders: a randomized controlled trial. Mol Autism 3(1):16. https://doi.org/10.1186/2040-2392-3-16.

Andari E, Duhamel J-R, Zalla T, Herbrecht E, Leboyer M, Sirigu A. 2010. Promoting social behavior with oxytocin in high-functioning autism spectrum disorders. Proc Natl Acad Sci U S A 107(9):4389-94. https://doi.org/10.1073/ pnas.0910249107.

Andreasen NC. 2008. The relationship between creativity and mood disorders. Dialogues Clin Neurosci 10(2):251-5.

Aoki Y, Yahata N, Watanabe T, Takano Y, Kawakubo Y, Kuwabara H, and others. 2014. Oxytocin improves behavioural and neural deficits in inferring others' social emotions in autism. Brain 137(pt 11):3073-86. https://doi. org/10.1093/brain/awu231.

Apps MAJ, Balsters JH, Ramnani N. 2012. The anterior cingulate cortex: monitoring the outcomes of others' decisions. Soc Neurosci 7(4):424-35. https://doi.org/10.1080/174709 19.2011.638799.

Apps MAJ, Lesage E, Ramnani N. 2015. Vicarious reinforcement learning signals when instructing others. J Neurosci 35(7):2904-13. https://doi.org/10.1523/ JNEUROSCI.3669-14.2015.

Apps MAJ, Lockwood PL, Balsters JH. 2013. The role of the midcingulate cortex in monitoring others' decisions. Front Neurosci 7:251. https://doi.org/10.3389/fnins.2013.00251.

Apps MAJ, Rushworth MFS, Chang SWC. 2016. The anterior cingulate gyrus and social cognition: tracking the motivation of others. Neuron 90(4):692-707. https://doi. org/10.1016/j.neuron.2016.04.018.
Aron AR, Robbins TW, Poldrack RA. 2004. Inhibition and the right inferior frontal cortex. Trends Cogn Sci 8(4):170-7. https://doi.org/10.1016/j.tics.2004.02.010.

Atsak P, Orre M, Bakker P, Cerliani L, Roozendaal B, Gazzola V, and others. 2011. Experience modulates vicarious freezing in rats: a model for empathy. PLoS One 6(7):e21855. https://doi.org/10.1371/journal.pone.0021855.

Avale ME, Chabout J, Pons S, Serreau P, De Chaumont F, OlivoMarin J-C, and others. 2011. Prefrontal nicotinic receptors control novel social interaction between mice. FASEB J 25(7):2145-55. https://doi.org/10.1096/fj.10-178558.

Badura A, Verpeut JL, Metzger JW, Pereira TD, Pisano TJ, Deverett B, and others. 2018. Normal cognitive and social development require posterior cerebellar activity. ELife 7:e36401. https://doi.org/10.7554/eLife.36401.

Balsters JH, Apps MAJ, Bolis D, Lehner R, Gallagher L, Wenderoth N. 2017. Disrupted prediction errors index social deficits in autism spectrum disorder. Brain 140(1):235-46. https://doi.org/10.1093/brain/aww287.

Balsters JH, Mantini D, Wenderoth N. 2018. Connectivitybased parcellation reveals distinct cortico-striatal connectivity fingerprints in autism spectrum disorder. Neuroimage 170:412-23. https://doi.org/10.1016/j.neuroimage.2017.02.019.

Balsters JH, Zerbi V, Sallet J, Wenderoth N, Mars RB. 2019. Primate homologs of mouse cortico-striatal circuits. Elife 9:e53680. https://doi.org/10.7554/elife.53680.

Barbas H, Pandya DN. 1989. Architecture and intrinsic connections of the prefrontal cortex in the rhesus monkey. $\mathrm{J}$ Comp Neurol 286(3):353-75. https://doi.org/10.1002/ cne. 902860306.

Bardi L, Six P, Brass M. 2017. Repetitive TMS of the temporoparietal junction disrupts participant's expectations in a spontaneous theory of mind task. Soc Cogn Affect Neurosci 12(11):1775-82. https://doi.org/10.1093/scan/nsx109.

Bariselli S, Tzanoulinou S, Glangetas C, Prévost-Solié C, Pucci L, Viguié J, and others. 2016. SHANK3 controls maturation of social reward circuits in the VTA. Nat Neurosci 19(7):926-34. https://doi.org/10.1038/nn.4319.

Baron-Cohen S, Leslie AM, Frith U. 1985. Does the autistic child have a "theory of mind"? Cognition 21(1):37-46. https://doi.org/10.1016/0010-0277(85)90022-8.

Baron-Cohen S. 2000. "Theory of Mind and Autism: A Review." In International Review of Research in Mental Retardation, 23:169-84. Autism. Academic Press. https:// doi.org/10.1016/S0074-7750(00)80010-5.

Barrash J, Tranel D, Anderson SW. 2000. Acquired personality disturbances associated with bilateral damage to the ventromedial prefrontal region. Dev Neuropsychol 18(3):355-81. https://doi.org/10.1207/S1532694205Barrash.

Bartra O, McGuire JT, Kable JW. 2013. The valuation system: a coordinate-based meta-analysis of BOLD FMRI experiments examining neural correlates of subjective value. Neuroimage 76:412-27. https://doi.org/10.1016/j.neuroimage.2013.02.063.

Baskerville TA, Douglas AJ. 2010. Dopamine and oxytocin interactions underlying behaviors: potential contributions to behavioral disorders. CNS Neurosci Ther 16(3):e92-123. https://doi.org/10.1111/j.1755-5949.2010.00154.x. 
Baumann O, Mattingley JB. 2012. Functional topography of primary emotion processing in the human cerebellum. Neuroimage 61(4):805-11. https://doi.org/10.1016/j.neuroimage.2012.03.044.

Baumgartner T, Schiller B, Rieskamp J, Gianotti LR, Knoch D. 2014. Diminishing parochialism in intergroup conflict by disrupting the right temporo-parietal junction. Soc Cogn Affect Neurosci 9(5):653-60. https://doi.org/10.1093/scan/ nst023.

Bechara A, Damasio H, Damasio AR. 2000. Emotion, decision making and the orbitofrontal cortex. Cereb Cortex 10(3):295-307. https://doi.org/10.1093/cercor/10.3.295.

Behrens TEJ, Hunt LT, Woolrich MW, Rushworth MFS. 2008. Associative learning of social value. Nature 456(7219):245-9. https://doi.org/10.1038/nature07538.

Beier KT, Steinberg EE, DeLoach KE, Xie S, Miyamichi K, Schwarz L, and others. 2015. Circuit architecture of VTA dopamine neurons revealed by systematic input-output mapping. Cell 162(3):622-34. https://doi.org/10.1016/j. cell.2015.07.015.

Ben-Ami Bartal I, Rodgers DA, Sarria MSB, Decety J, Mason P. 2014. Pro-social behavior in rats is modulated by social experience. Elife 3:e01385. https://doi.org/10.7554/eLife.01385.

Benekareddy M, Stachniak TJ, Bruns A, Knoflach F, von Kienlin M, Künnecke B, and others. 2018. Identification of a corticohabenular circuit regulating socially directed behavior. Biol Psychiatry 83(7):607-17. https://doi.org/10.1016/j.bio psych.2017.10.032.

Beny-Shefer Y, Zilkha N, Lavi-Avnon Y, Bezalel N, Rogachev I, Brandis A, and others. 2017. Nucleus accumbens dopamine signaling regulates sexual preference for females in male mice. Cell Rep 21(11):3079-88. https://doi. org/10.1016/j.celrep.2017.11.062.

Bernal-Casas D, Lee HJ, Weitz AJ, Lee JH. 2017. Studying brain circuit function with dynamic causal modeling for optogenetic FMRI. Neuron 93(3):522-32.e5. https://doi. org/10.1016/j.neuron.2016.12.035.

Berridge KC, Robinson TE. 1998. What is the role of dopamine in reward: hedonic impact, reward learning, or incentive salience? Brain Res Brain Res Rev 28(3):309-69. https:// doi.org/10.1016/s0165-0173(98)00019-8.

Berridge KC, Robinson TE. 2003. Parsing reward. Trends Neurosci 26(9):507-13. https://doi.org/10.1016/S01662236(03)00233-9.

Berridge KC, Robinson TE, Aldridge JW. 2009. Dissecting components of reward: 'liking', 'wanting', and learning. Curr Opin Pharmacol 9(1):65-73. https://doi.org/10.1016/j. coph.2008.12.014

Bhanji P, Delgado MR. 2014. The social brain and reward: social information processing in the human striatum. Wiley Interdiscip Rev Cogn Sci 5(1):61-73. https://doi. org/10.1002/wcs. 1266 .

Bickart KC, Wright CI, Dautoff RJ, Dickerson BC, Barrett LF. 2011. Amygdala volume and social network size in humans. Nat Neurosci 14(2):163-4. https://doi.org/10.1038 /nn.2724.

Bicks LK, Koike H, Akbarian S, Morishita H. 2015. Prefrontal cortex and social cognition in mouse and man. Front Psychol 6:1805. https://doi.org/10.3389/fpsyg.2015.01805.
Bicks LK, Yamamuro K, Flanigan ME, Kim JM, Kato D, Lucas EK, and others. 2020. Prefrontal parvalbumin interneurons require juvenile social experience to establish adult social behavior. Nat Commun 11(1):1003. https://doi. org/10.1038/s41467-020-14740-z.

Blair-West LF, Hoy KE, Hall PJ, Fitzgerald PB, Fitzgibbon BM. 2018. No change in social decision-making following transcranial direct current stimulation of the right temporoparietal junction. Front Neurosci 12:258. https://doi. org/10.3389/fnins.2018.00258.

Brischoux F, Chakraborty S, Brierley DI, Ungless MA. 2009. Phasic excitation of dopamine neurons in ventral VTA by noxious stimuli. Proc Natl Acad Sci U S A 106(12):48949. https://doi.org/10.1073/pnas.0811507106.

Brumback AC, Ellwood IT, Kjaerby C, Iafrati J, Robinson S, Lee AT, and others. 2018. Identifying specific prefrontal neurons that contribute to autism-associated abnormalities in physiology and social behavior. Mol Psychiatry 23(10):2078-89. https://doi.org/10.1038/mp.2017.213.

Buckner RL, Krienen FM, Castellanos A, Diaz JC, Yeo BT. 2011. The organization of the human cerebellum estimated by intrinsic functional connectivity. J Neurophysiol 106(5):2322-45. https://doi.org/10.1152/ jn.00339.2011.

Budygin EA, Park J, Bass CE, Grinevich VP, Bonin KD, Wightman RM. 2012. Aversive stimulus differentially triggers subsecond dopamine release in reward regions. Neuroscience 201:331-7. https://doi.org/10.1016/j.neuroscience.2011.10.056

Cao W, Lin S, Xia QQ, Du Y-L, Yang Q, Zhang M-Y, and others. 2018. Gamma oscillation dysfunction in mPFC leads to social deficits in neuroligin $3 \mathrm{R} 451 \mathrm{C}$ knockin mice. Neuron 97(6):1253-60.e7. https://doi.org/10.1016/j.neuron.2018.02.001.

Carlén M. 2017. What constitutes the prefrontal cortex? Science 358(6362):478-82. https://doi.org/10.1126/science.aan8868.

Carta I, Chen CH, Schott AL, Dorizan S, Khodakhah K. 2019. Cerebellar modulation of the reward circuitry and social behavior. Science 363(6424):eaav0581. https://doi. org/10.1126/science.aav0581.

Carter RM, Macinnes JJ, Huettel SA, Adcock RA. 2009. Activation in the VTA and nucleus accumbens increases in anticipation of both gains and losses. Front Behav Neurosci 3:21. https://doi.org/10.3389/neuro.08.021.2009.

Chaudhury D, Walsh JJ, Friedman AK, Juarez B, Ku SM, Koo JW, and others. 2013. Rapid regulation of depressionrelated behaviours by control of midbrain dopamine neurons. Nature 493(7433):532-6. https://doi.org/10.1038/ nature 11713.

Chen P, Hong W. 2018. Neural circuit mechanisms of social behavior. Neuron 98(1):16-30. https://doi.org/10.1016/j. neuron.2018.02.026.

Chevallier C, Kohls G, Troiani V, Brodkin ES, Schultz RT. 2012. The social motivation theory of autism. Trends Cogn Sci 16(4):231-9. https://doi.org/10.1016/j.tics.2012.02.007.

Choe KY, Sanchez CF, Harris NG, Otis TS, Mathews PJ. 2018. Optogenetic fMRI and electrophysiological identification of region-specific connectivity between the cerebellar 
cortex and forebrain. Neuroimage 173:370-83. https://doi. org/10.1016/j.neuroimage.2018.02.047.

Christie IN, Wells JA, Kasparov S, Gourine AV, Lythgoe MF. 2017. Volumetric spatial correlations of neurovascular coupling studied using single pulse Opto-FMRI. Sci Rep 7:41583. https://doi.org/10.1038/srep41583.

Courchesne E, Yeung-Courchesne R, Press GA, Hesselink JR, Jernigan TL. 1988. Hypoplasia of cerebellar vermal lobules VI and VII in autism. N Engl J Med 318(21):1349-54. https://doi.org/10.1056/NEJM198805263182102.

Crespi BJ. 2001. The evolution of social behavior in microorganisms. Trends Ecol Evol 16(4):178-83. https://doi. org/10.1016/s0169-5347(01)02115-2

Daenen EWPM, Wolterink G, Van Der Heyden JA, Kruse CG, Van Ree JM. 2003. Neonatal lesions in the amygdala or ventral hippocampus disrupt prepulse inhibition of the acoustic startle response; implications for an animal model of neurodevelopmental disorders like schizophrenia. Eur Neuropsychopharmacol 13(3):187-97. https://doi. org/10.1016/s0924-977x(03)00007-5.

Dang TP, Mattan BD, Kubota JT, Cloutier J. 2019. The ventromedial prefrontal cortex is particularly responsive to social evaluations requiring the use of person-knowledge. Sci Rep 9(1):5054. https://doi.org/10.1038/s41598-019-41544-z.

Daniel R, Pollmann S. 2014. A universal role of the ventral striatum in reward-based learning: evidence from human studies. Neurobiol Learn Mem 0:90-100. https://doi. org/10.1016/j.nlm.2014.05.002.

Dawson G, Carver L, Meltzoff AN, Panagiotides H, McPartland J, Webb SJ. 2002. Neural correlates of face and object recognition in young children with autism spectrum disorder, developmental delay, and typical development. Child Dev 73(3):700-17. https://doi.org/10.1111/1467-8624.00433.

de Quervain DJ-Fde, Fischbacher U, Treyer V, Schellhammer M, Schnyder U, Buck A, and others. 2004. The neural basis of altruistic punishment. Science 305(5688):1254-8. https://doi.org/10.1126/science.1100735.

Decety J, Lamm C. 2007. The role of the right temporoparietal junction in social interaction: how low-level computational processes contribute to meta-cognition. Neuroscientist 13(6):580-93. https://doi.org/10.1177/1073858407304654.

Ebstein RP, Israel S, Chew SH, Zhong S, Knafo A. 2010. Genetics of human social behavior. Neuron 65(6):831-44. https://doi.org/10.1016/j.neuron.2010.02.020.

Eisenberg N, Eggum ND, Di Giunta L. 2010. Empathy-related responding: associations with prosocial behavior, aggression, and intergroup relations. Soc Issues Policy Rev 4(1):143-80. https://doi.org/10.1111/j.1751-2409.2010.01020.x.

Eisenegger C, Pedroni A, Rieskamp J, Zehnder C, Ebstein R, Fehr E, and others. 2013. DAT1 polymorphism determines L-DOPA effects on learning about others' prosociality. PLoS One 8(7):e67820. https://doi.org/10.1371/journal. pone.0067820.

Fehr E, Camerer CF. 2007. Social neuroeconomics: the neural circuitry of social preferences. Trends Cogn Sci 11(10):419-27. https://doi.org/10.1016/j.tics.2007.09.002.

Felix-Ortiz AC, Burgos-Robles A, Bhagat ND, Leppla CA, Tye KM. 2016. Bidirectional modulation of anxiety-related and social behaviors by amygdala projections to the medial prefrontal cortex. Neuroscience 321:197-209. https://doi. org/10.1016/j.neuroscience.2015.07.041.

Felix-Ortiz AC, Tye KM. 2014. Amygdala Inputs to the ventral hippocampus bidirectionally modulate social behavior. J Neurosci 34(2):586-95. https://doi.org/10.1523/ JNEUROSCI.4257-13.2014.

Ferenczi EA, Zalocusky KA, Liston C, Grosenick L, Warden MR, Amatya D, and others. 2016. Prefrontal cortical regulation of brainwide circuit dynamics and rewardrelated behavior. Science 351(6268):aac9698. https://doi. org/10.1126/science.aac9698.

Finlayson G, Arlotti A, Dalton M, King N, Blundell JE. 2011. Implicit wanting and explicit liking are markers for trait binge eating. A susceptible phenotype for overeating. Appetite 57(3):722-8. https://doi.org/10.1016/j. appet.2011.08.012.

Freese JL, Amaral DG. 2009. Neuroanatomy of the Primate Amygdala. In The Human Amygdala, 3-42. New York, NY, US: Guilford Press.

Frith C. 1996. Brain mechanisms for 'Having a Theory of Mind.' J Psychopharmacol 10(1):9-15. https://doi. org/10.1177/026988119601000103.

Frith CD. 2007. The social brain? Philos Trans R Soc Lond B Biol Sci 362(1480):671-8. https://doi.org/10.1098/rstb .2006.2003.

Frith CD, Frith U. 2006. The neural basis of mentalizing. Neuron 50(4):531-4. https://doi.org/10.1016/j.neuron.2006 .05.001.

Fudge JL, Kelly EA, Pal R, Bedont JL, Park L, Ho B. 2017. Beyond the classic VTA: extended amygdala projections to DA-striatal paths in the primate. Neuropsychopharmacology 42(8):1563-76. https://doi.org/10.1038/npp.2017.38.

Fulford D, Campellone T, Gard DE. 2018. Social motivation in schizophrenia: how research on basic reward processes informs and limits our understanding. Clin Psychol Rev 63:12-24. https://doi.org/10.1016/j.cpr.2018.05.007.

Ghashghaei HT, Hilgetag CC, Barbas H. 2007. Sequence of information processing for emotions based on the anatomic dialogue between prefrontal cortex and amygdala. Neuroimage 34(3):905-23. https://doi.org/10.1016/j.neuroimage.2006.09.046.

Giménez M, Pujol J, Ortiz H, Soriano-Mas C, López-Solà M, Farré M, and others. 2012. Altered brain functional connectivity in relation to perception of scrutiny in social anxiety disorder. Psychiatry Res 202(3):214-23. https://doi. org/10.1016/j.pscychresns.2011.10.008.

Goodson JL. 2013. Deconstructing sociality, social evolution and relevant nonapeptide functions. Psychoneuroendocrinology 38(4):465-78. https://doi.org/10.1016/j. psyneuen.2012.12.005.

Gordon I, Jack A, Pretzsch CM, Wyk BV, Leckman JF, Feldman R, and others. 2016. Intranasal oxytocin enhances connectivity in the neural circuitry supporting social motivation and social perception in children with autism. Sci Rep 6:35054. https://doi.org/10.1038/srep35054.

Gregory R, Cheng H, Rupp H, Sengelaub DR, Heiman JR. 2015. Oxytocin increases VTA activation to infant and sexual stimuli in nulliparous and postpartum women. Horm Behav 69:82-8. https://doi.org/10.1016/j.yhbeh.2014.12.009. 
Grinevich V, Stoop R. 2018. Interplay between oxytocin and sensory systems in the orchestration of socio-emotional behaviors. Neuron 99(5):887-904. https://doi. org/10.1016/j.neuron.2018.07.016.

Groppe SE, Gossen A, Rademacher L, Hahn A, Westphal L, Gründer G, and others. 2013. Oxytocin influences processing of socially relevant cues in the ventral tegmental area of the human brain. Biol Psychiatry 74(3):172-9. https://doi. org/10.1016/j.biopsych.2012.12.023.

Gross CT, Canteras NS. 2012. The many paths to fear. Nat Rev Neurosci 13(9):651-8. https://doi.org/10.1038/nrn3301.

Guastella AJ, Gray KM, Rinehart NJ, Alvares GA, Tonge BJ, Hickie IB, and others. 2015. The effects of a course of intranasal oxytocin on social behaviors in youth diagnosed with autism spectrum disorders: a randomized controlled trial. J Child Psychol Psychiatry 56(4):444-52. https://doi. org/10.1111/jcpp.12305.

Gunaydin LA, Grosenick L, Finkelstein JC, Kauvar IV, Fenno LE, Adhikari A, and others. 2014. Natural neural projection dynamics underlying social behavior. Cell 157(7):153551. https://doi.org/10.1016/j.cell.2014.05.017.

Guo X, Zheng L, Cheng X, Chen M, Zhu L, Li J, and others. 2014. Neural responses to unfairness and fairness depend on self-contribution to the income. Soc Cogn Affect Neurosci 9(10):1498-505. https://doi.org/10.1093/scan/nst131.

Hall FS, Wilkinson LS, Humby T, Robbins TW. 1999. Maternal deprivation of neonatal rats produces enduring changes in dopamine function. Synapse 32(1):37-43. https://doi. org/10.1002/(SICI)1098-2396(199904)32:1<37::AIDSYN5 $>3.0 . C O ; 2-4$.

Halko ML, Y Hlushchuk, R Hari, and M Schürmann. 2009. Competing with peers: mentalizing-related brain activity reflects what is at stake. Neuroimage 46(2):542-8. https:// doi.org/10.1016/j.neuroimage.2009.01.063.

Han X, Jing MY, Zhao TY, Wu N, Song R, Li J. 2017. Role of dopamine projections from ventral tegmental area to nucleus accumbens and medial prefrontal cortex in reinforcement behaviors assessed using optogenetic manipulation. Metab Brain Dis 32(5):1491-502. https://doi. org/10.1007/s11011-017-0023-3.

Han Y, Bruls R, Soyman E, Thomas RM, Pentaraki V, Jelinek N, and others. 2019. Bidirectional cingulate-dependent danger information transfer across rats. PLoS Biol 17(12):e3000524. https://doi.org/10.1371/journal.pbio.3000524.

Heilbronner SR, Rodriguez-Romaguera J, Quirk GJ, Groenewegen HJ, Haber SN. 2016. Circuit-based corticostriatal homologies between rat and primate. Biol Psychiatry 80(7):509-21. https://doi.org/10.1016/j.biopsych.2016.05.012.

Hétu S, Luo Y, D’Ardenne K, Lohrenz T, Montague PR. 2017. Human substantia nigra and ventral tegmental area involvement in computing social error signals during the ultimatum game. Soc Cogn Affect Neurosci 12(12):197282. https://doi.org/10.1093/scan/nsx097.

Hill CA, Suzuki S, Polania R, Moisa M, O’Doherty JP, Ruff CC. 2017. A causal account of the brain network computations underlying strategic social behavior. Nat Neurosci 20(8):1142-9. https://doi.org/10.1038/nn.4602.
Hill MR, Boorman ED, Fried I. 2016. Observational learning computations in neurons of the human anterior cingulate cortex. Nat Commun 7:12722. https://doi.org/10.1038/ ncomms 12722 .

Hillman KL, Bilkey DK. 2012. Neural encoding of competitive effort in the anterior cingulate cortex. Nat Neurosci 15(9):1290-7. https://doi.org/10.1038/nn.3187.

Hong W, Kim DW, Anderson DJ. 2014. Antagonistic control of social versus repetitive self-grooming behaviors by separable amygdala neuronal subsets. Cell 158(6):1348-61. https://doi.org/10.1016/j.cell.2014.07.049.

Hooker CI, Verosky SC, Germine LT, Knight RT, D’Esposito M. 2010. Neural activity during social signal perception correlates with self-reported empathy. Brain Res 1308:100 13. https://doi.org/10.1016/j.brainres.2009.10.006.

Horea H-I, Saab BJ, Rudin M. 2020. A whole-brain map and assay parameter analysis of mouse VTA dopaminergic activation. bioRxiv. https://doi.org/10.1101/2020.04.03.023648.

Howes SR, Dalley JW, Morrison CH, Robbins TW, Everitt BJ. 2000. Leftward shift in the acquisition of cocaine selfadministration in isolation-reared rats: relationship to extracellular levels of dopamine, serotonin and glutamate in the nucleus accumbens and amygdala-striatal FOS expression. Psychopharmacology 151(1):55-63.

$\mathrm{Hu}$ J, Qi S, Becker B, Luo L, Gao S, Gong Q, and others. 2015. Oxytocin selectively facilitates learning with social feedback and increases activity and functional connectivity in emotional memory and reward processing regions. Hum Brain Mapp 36(6):2132-46. https://doi.org/10.1002/ hbm.22760.

Hung LW, Neuner S, Polepalli JS, Beier KT, Wright M, Walsh JJ, and others. 2017. Gating of social reward by oxytocin in the ventral tegmental area. Science 357(6358):1406-11. https://doi.org/10.1126/science.aan4994.

Javaheri ESSJ, Bigdeli MR, Zibaii MI, Dargahi L, Pouretemad HR. 2019. Optogenetic stimulation of the anterior cingulate cortex ameliorates autistic-like behaviors in rats induced by neonatal isolation, caudate putamen as a site for alteration. Neuromol Med 21(2):132-42. https://doi.org/10.1007/ s12017-019-08526-w.

Jeurissen D, Sack AT, Roebroeck A, Russ BE, Pascual-Leone A. 2014. TMS affects moral judgment, showing the role of DLPFC and TPJ in cognitive and emotional processing. Front Neurosci 8:18. https://doi.org/10.3389/ fnins.2014.00018.

Johnson FK, Delpech J-C, Thompson GJ, Wei L, Hao J, Herman P, and others. 2018. Amygdala hyper-connectivity in a mouse model of unpredictable early life stress. Transl Psychiatry 8(1):49. https://doi.org/10.1038/s41398-0180092-z.

Joiner J, Piva M, Turrin C, Chang SWC. 2017. Social learning through prediction error in the brain. NPJ Sci Learn 2:8. https://doi.org/10.1038/s41539-017-0009-2.

Kaidanovich-Beilin O, Lipina T, Vukobradovic I, Roder J, Woodgett JR. 2011. Assessment of social interaction behaviors. J Vis Exp 48:2473. https://doi.org/10.3791/2473.

Kas MJ, Modi ME, Saxe MD, Smith DG. 2014. Advancing the discovery of medications for autism spectrum disorder 
using new technologies to reveal social brain circuitry in rodents. Psychopharmacology 231(6):1147-65. https://doi. org/10.1007/s00213-014-3464-y.

Kelly RM, Strick PL. 2003. Cerebellar loops with motor cortex and prefrontal cortex of a nonhuman primate. J Neurosci 23(23):8432-44.

Kelly YT, Webb TW, Meier JD, Arcaro MJ, Graziano MS. 2014. Attributing awareness to oneself and to others. Proc Natl Acad Sci U S A 111(13):5012-7. https://doi. org/10.1073/pnas.1401201111.

Kirsch P, Schienle A, Stark R, Sammer G, Blecker C, Walter B, and others. 2003. Anticipation of reward in a nonaversive differential conditioning paradigm and the brain reward system: an event-related FMRI study. Neuroimage 20(2):108695. https://doi.org/10.1016/S1053-8119(03)00381-1.

Kishida KT, Saez I, Lohrenz T, Witcher MR, Laxton AW, Tatter SB, and others. 2016. Subsecond dopamine fluctuations in human striatum encode superposed error signals about actual and counterfactual reward. Proc Natl Acad Sci U S A 113(1):200-5. https://doi.org/10.1073/pnas.1513619112.

Kishida KT, Sandberg SG, Lohrenz T, Comair YG, Sáez I, Phillips PEM, and others. 2011. Sub-second dopamine detection in human striatum. PLoS One 6(8):e23291. https://doi.org/10.1371/journal.pone.0023291.

Knobloch HS, Charlet A, Hoffmann LC, Eliava M, Khrulev S, Cetin AH, and others. 2012. Evoked axonal oxytocin release in the central amygdala attenuates fear response. Neuron 73(3):553-66. https://doi.org/10.1016/j.neuron.2011.11.030.

Knutson B, Westdorp A, Kaiser E, Hommer D. 2000. FMRI visualization of brain activity during a monetary incentive delay task. Neuroimage 12(1):20-7. https://doi. org/10.1006/nimg.2000.0593.

Kohls G, Schulte-Rüther M, Nehrkorn B, Müller K, Fink GR, Kamp-Becker I, and others. 2013. Reward system dysfunction in autism spectrum disorders. Soc Cogn Affect Neurosci 8(5):565-72. https://doi.org/10.1093/scan/nss033.

Kondrakiewicz K, Kostecki M, Szadzińska W, Knapska E. 2018. Ecological validity of social interaction tests in rats and mice. Genes Brain Behav 18(1):e12525. https://doi. org/10.1111/gbb.12525.

Krall SC, Rottschy C, Oberwelland E, Bzdok D, Fox PT, Eickhoff $\mathrm{SB}$, and others. 2015. The role of the right temporoparietal junction in attention and social interaction as revealed by ALE meta-analysis. Brain Struct Funct 220(2):587-604. https://doi.org/10.1007/s00429-014-0803-z.

Krishnamurti T, Loewenstein G. 2012. The partner-specific sexual liking and sexual wanting scale: psychometric properties. Arch Sex Behav 41(2):467-76. https://doi. org/10.1007/s10508-011-9785-6.

Laird AR, Fox PM, Eickhoff SB, Turner JA, Ray KL, D. McKay $\mathrm{R}$, and others. 2011. Behavioral interpretations of intrinsic connectivity networks. J Cogn Neurosci 23(12):4022-37. https://doi.org/10.1162/jocn_a_00077.

Lammel S, Hetzel A, Häckel O, Jones I, Liss B, Roeper J. 2008. Unique properties of mesoprefrontal neurons within a dual mesocorticolimbic dopamine system. Neuron 57(5):76073. https://doi.org/10.1016/j.neuron.2008.01.022.

Lang D-LY, Bamshad M, Dorcely R. 2019. Pattern of Fos activation in the ventral tegmental area (VTA) of male prairie vole's (Microtus Ochrogaster) in response to infant-related stimuli. Brain Res 1714:119-25. https://doi.org/10.1016/j. brainres.2019.02.023.

Lansford JE, Dodge KA, Pettit GS, Bates JE, Crozier J, Kaplow J. 2002. A 12-year prospective study of the long-term effects of early child physical maltreatment on psychological, behavioral, and academic problems in adolescence. Arch Pediatr Adolesc Med 156(8):824-30.

Laricchiuta D, Petrosini L. 2014. Individual differences in response to positive and negative stimuli: endocannabinoidbased insight on approach and avoidance behaviors. Front Syst Neurosci 8. https://doi.org/10.3389/fnsys.2014.00238.

Laubach M, Amarante LM, Swanson K, White SR. 2018. What, if anything, is rodent prefrontal cortex? eNeuro 5(5):ENEURO.0315-18.2018. https://doi.org/10.1523/ ENEURO.0315-18.2018.

Lee JH. 2012. Informing brain connectivity with optogenetic functional magnetic resonance imaging. Neuroimage 62(4): 2244-9. https://doi.org/10.1016/j.neuroimage.2012.01.116.

Lee JH, Durand R, Gradinaru V, Zhang F, Goshen I, Kim D-S, and others. 2010. Global and local FMRI signals driven by neurons defined optogenetically by type and wiring. Nature 465(7299):788-92. https://doi.org/10.1038/nature09108.

Li W, Mai X, Liu C. 2014. The default mode network and social understanding of others: what do brain connectivity studies tell us. Front Hum Neurosci 8:74. https://doi.org/10.3389/ fnhum.2014.00074.

Liu H, Liao J, Jiang W, Wang W. 2014. Changes in low-frequency fluctuations in patients with antisocial personality disorder revealed by resting-state functional MRI. PLoS One 9(3):e89790. https://doi.org/10.1371/journal.pone.0089790.

Liu Y, Li S, Lin W, Li W, Yan X, Wang X, and others. 2019. Oxytocin modulates social value representations in the amygdala. Nat Neurosci 22(4):633. https://doi.org/10.1038/ s41593-019-0351-1.

Lockwood PL. 2016. The anatomy of empathy: vicarious experience and disorders of social cognition. Behav Brain Res 311:255-66. https://doi.org/10.1016/j.bbr.2016.05.048.

Lockwood PL, Apps MAJ, Roiser JP, Viding E. 2015. Encoding of vicarious reward prediction in anterior cingulate cortex and relationship with trait empathy. J Neurosci 35(40):13720-7. https://doi.org/10.1523/ JNEUROSCI.1703-15.2015.

Lockwood PL, Wittmann MK, Apps MAJ, Klein-Flügge MC, Crockett MJ, Humphreys GW, and others. 2018. Neural mechanisms for learning self and other ownership. Nat Commun 9(1):4747. https://doi.org/10.1038/s41467-018-07231-9.

Lohani S, Poplawsky AJ, Kim S-G, Moghaddam B. 2017. Unexpected global impact of VTA dopamine neuron activation as measured by opto-FMRI. Mol Psychiatry 22(4):585-94. https://doi.org/10.1038/mp.2016.102.

Lukas M, Toth I, Reber SO, Slattery DA, Veenema AH, Neumann ID. 2011. The neuropeptide oxytocin facilitates pro-social behavior and prevents social avoidance in rats and mice. Neuropsychopharmacology 36(11):2159-68. https://doi.org/10.1038/npp.2011.95.

Luo J. 2018. The neural basis of and a common neural circuitry in different types of pro-social behavior. Front Psychol 9. https://doi.org/10.3389/fpsyg.2018.00859. 
Margolis EB, Lock H, Hjelmstad GO, Fields HL. 2006. The ventral tegmental area revisited: is there an electrophysiological marker for dopaminergic neurons? J Physiol 577(pt 3):907-24. https://doi.org/10.1113/jphysiol.2006 .117069 .

Marlin BJ, Froemke RC. 2017. Oxytocin modulation of neural circuits for social behavior. Dev Neurobiol 77(2):169-89. https://doi.org/10.1002/dneu.22452.

Marlin BJ, Mitre M, D'amour JA, Chao MV, Froemke RC. 2015. Oxytocin enables maternal behaviour by balancing cortical inhibition. Nature 520(7548):499-504. https://doi. org/10.1038/nature14402.

Mars RB, Sallet J, Neubert FX, Rushworth MF. 2013. Connectivity profiles reveal the relationship between brain areas for social cognition in human and monkey temporoparietal cortex. Proc Natl Acad Sci U S A 110(26):1080611. https://doi.org/10.1073/pnas.1302956110.

Mars RB, Neubert F-X, Noonan MAP, Sallet J, Toni I, Rushworth MFS. 2012. On the relationship between the 'Default Mode Network' and the 'Social Brain.' Front Hum Neurosci 6. https://doi.org/10.3389/fnhum.2012.00189.

Mars RB, Sallet J, Schüffelgen U, Jbabdi S, Toni I, Rushworth MF. 2012. Connectivity-based subdivisions of the human right "temporoparietal junction area": evidence for different areas participating in different cortical networks. Cereb Cortex 22(8):1894-903. https://doi.org/10.1093/cercor/ bhr268.

Martino BD, Bobadilla-Suarez S, Nouguchi T, Sharot T, Love BC. 2017. Social information is integrated into value and confidence judgments according to its reliability. J Neurosci 37(25):6066-74. https://doi.org/10.1523/ JNEUROSCI.3880-16.2017.

Mazza M, Pino MC, Mariano M, Tempesta D, Ferrara M, Berardis DD, and others. 2014. Affective and cognitive empathy in adolescents with autism spectrum disorder. Front Hum Neurosci 8. https://doi.org/10.3389/fnhum .2014.00791.

McClure SM, Ericson KM, Laibson DI, Loewenstein G, Cohen JD. 2007. Time discounting for primary rewards. J Neurosci 27(21):5796-804. https://doi.org/10.1523/ JNEUROSCI.4246-06.2007.

Menon M, Jensen J, Vitcu I, Graff-Guerrero A, Crawley A, Smith MA, and others. 2007. Temporal difference modeling of the blood-oxygen level dependent response during aversive conditioning in humans: effects of dopaminergic modulation. Biol Psychiatry 62(7):765-72. https://doi. org/10.1016/j.biopsych.2006.10.020.

Meshi D, Morawetz C, Heekeren HR. 2013. Nucleus accumbens response to gains in reputation for the self relative to gains for others predicts social media use. Front Hum Neurosci 7. https://doi.org/10.3389/fnhum.2013.00439.

Middleton FA, Strick PL. 2000. Basal ganglia and cerebellar loops: motor and cognitive circuits. Brain Res Rev 31 (2-3):236-50.

Mier D, Kirsch P. 2017. Social-cognitive deficits in schizophrenia. Curr Topics Behav Neurosci 30:397-409. https://doi. org/10.1007/7854_2015_427.

Mikhailova MA, Bass CE, Grinevich VP, Chappell AM, Deal AL, Bonin KD, and others. 2016. Optogenetically-induced tonic dopamine release from VTA-nucleus accumbens projections inhibits reward consummatory behaviors. Neuroscience 333:54-64. https://doi.org/10.1016/j.neuroscience.2016 .07 .006 .

Miller G. 2013. The promise and perils of oxytocin. Science 339(6117):267-9. https://doi.org/10.1126/science.339 .6117 .267 .

Moll J, Krueger F, Zahn R, Pardini M, Oliveira-Souza Rd, Grafman J. 2006. Human fronto-mesolimbic networks guide decisions about charitable donation. Proc Natl Acad Sci U S A 103(42):15623-8. https://doi.org/10.1073/ pnas.0604475103.

Moreno-Rius J. 2019. Is there an 'Antisocial' Cerebellum? evidence from disorders other than autism characterized by abnormal social behaviours. Prog Neuro-Psychopharmacol Biol Psychiatry 89:1-8. https://doi.org/10.1016/j. pnpbp.2018.08.025.

Morishima Y, Schunk D, Bruhin A, Ruff CC, Fehr E. 2012. Linking brain structure and activation in temporoparietal junction to explain the neurobiology of human altruism. Neuron 75(1):73-9. https://doi.org/10.1016/j. neuron.2012.05.021.

Morris JS, Friston KJ, Büchel C, Frith CD, Young AW, Calder AJ, and others. 1998. A neuromodulatory role for the human amygdala in processing emotional facial expressions. Brain J Neurol 121(pt 1): 47-57.

Morris JS, Frith CD, Perrett DI, Rowland D, Young AW, Calder AJ, and others. 1996. A differential neural response in the human amygdala to fearful and happy facial expressions. Nature 383(6603):812-5. https://doi. org/10.1038/383812a0.

Nakajima M, Görlich A, Heintz N. 2014. Oxytocin modulates female sociosexual behavior through a specific class of prefrontal cortical interneurons. Cell 159(2):295-305. https:// doi.org/10.1016/j.cell.2014.09.020.

Noritake A, Ninomiya T, Isoda M. 2018. Social reward monitoring and valuation in the macaque brain. Nat Neurosci 21(10):1452-62. https://doi.org/10.1038/s41593-018-0229-7.

O'Connell LA, Hofmann HA. 2011. The vertebrate mesolimbic reward system and social behavior network: a comparative synthesis. J Comp Neurol 519(18):3599-639. https://doi. org/10.1002/cne.22735.

O'Connell LA, Hofmann HA. 2012. Evolution of a vertebrate social decision-making network. Science 336(6085):1154 7. https://doi.org/10.1126/science.1218889.

Olsson A, Knapska E, Lindström B. 2020. The neural and computational systems of social learning. Nat Rev Neurosci 21(4):197-212. https://doi.org/10.1038/s41583020-02764.

Ometto M, de Oliveira PA, Milioni AL, Santos BD, Scivoletto S, Busatto GF, and others. 2016. Social skills and psychopathic traits in maltreated adolescents. Eur Child Adolesc Psychiatry 25(4):397-405. https://doi.org/10.1007/s00787015-0744-y.

Park AT, Leonard JA, Saxler PK, Cyr AB, Gabrieli JDE, Mackey AP. 2018. Amygdala-medial prefrontal cortex connectivity relates to stress and mental health in early childhood. Soc Cogn Affect Neurosci 13(4):430-9. https:// doi.org/10.1093/scan/nsy017. 
Passingham RE, Stephan KE, Kötter R. 2002. The anatomical basis of functional localization in the cortex. Nat Rev Neurosci 3(8):606-16. https://doi.org/10.1038/nrn893.

Patel JC, Rossignol E, Rice ME, Machold P. 2012. Opposing regulation of dopaminergic activity and exploratory motor behavior by forebrain and brainstem cholinergic circuits. Nat Commun 3:1172. https://doi.org/10.1038/ ncomms 2144 .

Pauli WM, O'Reilly RC, Yarkoni T, Wager TD. 2016. Regional specialization within the human striatum for diverse psychological functions. Proc Natl Acad Sci U S A 113(7):190712. https://doi.org/10.1073/pnas.1507610113.

Peñagarikano O, Lázaro MT, Lu X-H, Gordon A, Dong H, Lam HA, and others. 2015. Exogenous and evoked oxytocin restores social behavior in the Cntnap2 mouse model of autism. Sci Transl Med 7(271):271ra8. https://doi. org/10.1126/scitranslmed.3010257.

Prounis GS, Ophir AG. 2020. One cranium, two brains not yet introduced: distinct but complementary views of the social brain. Neurosci Biobehav Rev 108:231-45. https://doi. org/10.1016/j.neubiorev.2019.11.011.

Qin L, Ma K, Yan Z. 2019. Chemogenetic activation of prefrontal cortex in shank3-deficient mice ameliorates social deficits, NMDAR hypofunction, and Sgk2 downregulation. iScience 17:24-35. https://doi.org/10.1016/j. isci.2019.06.014.

Quintana DS, Rokicki J, van der Meer D, Alnæs D, Kaufmann T, Palomera AC, and others. 2017. Oxytocin gene networks in the human brain: a gene expression and large-scale FMRI meta-analysis study. BioRxiv 149526. https://doi. org/10.1101/149526.

Rademacher L, Krach S, Kohls G, Irmak A, Gründer G, Spreckelmeyer KN. 2010. Dissociation of neural networks for anticipation and consumption of monetary and social rewards. Neuroimage 49(4):3276-85. https://doi. org/10.1016/j.neuroimage.2009.10.089.

Rausch A, Zhang W, Beckmann CF, Buitelaar JK, Groen WB, Haak KV. 2018. Connectivity-based parcellation of the amygdala predicts social skills in adolescents with autism spectrum disorder. J Autism Dev Disord 48(2):572-82. https://doi.org/10.1007/s10803-017-3370-3.

Redcay E, Dodell-Feder D, Mavros PL, Kleiner M, Pearrow MJ, Triantafyllou C, and others. 2013. Atypical brain activation patterns during a face-to-face joint attention game in adults with autism spectrum disorder. Hum Brain Mapp 34(10):2511-23. https://doi.org/10.1002/hbm.22086.

Rennie SM, Moita MM, Mainen ZF. 2013. Social cognition in the rodent: nothing to be sniffed at. Trends Cogn Sci 17(7):306-7. https://doi.org/10.1016/j.tics.2013.04.011.

Riba J, Krämer UM, Heldmann M, Richter S, Münte TF. 2008. Dopamine agonist increases risk taking but blunts rewardrelated brain activity. PLoS One 3(6):e2479. https://doi. org/10.1371/journal.pone.0002479.

Rilling JK, Sanfey AG, Aronson JA, Nystrom LE, Cohen JD. 2004. The neural correlates of theory of mind within interpersonal interactions. Neuroimage 22(4):1694-703. https:// doi.org/10.1016/j.neuroimage.2004.04.015.

Robinson DL, Heien MLAV, Wightman RM. 2002. Frequency of dopamine concentration transients increases in dorsal and ventral striatum of male rats during introduction of conspecifics. J Neurosci 22(23):10477-86.

Robinson DL, Zitzman DL, Smith KJ, Spear LP. 2011. Fast dopamine release events in the nucleus accumbens of early adolescent rats. Neuroscience 176 296-307. https://doi. org/10.1016/j.neuroscience.2010.12.016.

Robinson DL, Zitzman DL, Williams SK. 2011. Mesolimbic dopamine transients in motivated behaviors: focus on maternal behavior. Front Psychiatry 2:23. https://doi. org/10.3389/fpsyt.2011.00023.

Robinson TE, Berridge KC. 1993. The neural basis of drug craving: an incentive-sensitization theory of addiction. Brain Res Rev 18(3):247-91.

Rudebeck PH, Buckley MJ, Walton ME, Rushworth MFS. 2006. A role for the macaque anterior cingulate gyrus in social valuation. Science 313(5791):1310-2. https://doi. org/10.1126/science.1128197.

Rudebeck PH, Walton ME, Millette BHP, Shirley E, Rushworth MFS, Bannerman DM. 2007. Distinct contributions of frontal areas to emotion and social behaviour in the rat. Eur J Neurosci 26(8):2315-26. https://doi.org/10.1111/j.14609568.2007.05844.x.

Ruff CC, Fehr E. 2014. The neurobiology of rewards and values in social decision making. Nat Rev Neurosci 15(8):549-62. https://doi.org/10.1038/nrn3776.

Rungta RL, Osmanski B-F, Boido D, Tanter M, Charpak S. 2017. Light controls cerebral blood flow in naive animals. Nat Commun 8:14191. https://doi.org/10.1038/ ncomms 14191 .

Rushworth MFS, Noonan MP, Boorman ED, Walton ME, Behrens TE. 2011. Frontal cortex and reward-guided learning and decision-making. Neuron 70(6):1054-69. https:// doi.org/10.1016/j.neuron.2011.05.014.

Russo SJ, Nestler EJ. 2013. The brain reward circuitry in mood disorders. Nat Rev Neurosci 14(9). https://doi.org/10.1038/ nrn3381.

Sangiamo DT, Warren MR, Neunuebel JP. 2020. Ultrasonic signals associated with different types of social behavior of mice. Nat Neurosci 23(3):411-22. https://doi.org/10.1038/ s41593-020-0584-z.

Santiesteban I, Banissy MJ, Catmur C, Bird G. 2012. Enhancing social ability by stimulating right temporoparietal junction. Curr Biol 22(23):2274-7. https://doi.org/10.1016/j. cub.2012.10.018.

Schmahmann JD. 1991. An emerging concept. The cerebellar contribution to higher function. Arch Neurol 48(11):1178-87.

Schmahmann JD. 2004. Disorders of the cerebellum: ataxia, dysmetria of thought, and the cerebellar cognitive affective syndrome. J Neuropsychiatry Clin Neurosci 16(3):367-78. https://doi.org/10.1176/jnp.16.3.367.

Schmahmann JD, Caplan D. 2006. Cognition, emotion and the cerebellum. Brain J Neurol 129(pt 2):290-2. https://doi. org/10.1093/brain/awh729.

Schmahmann JD, Sherman JC. 1998. The cerebellar cognitive affective syndrome. Brain J Neurol 121(pt 4):561-79. https://doi.org/10.1093/brain/121.4.561.

Schultz W, Dayan P, Montague PR. 1997. A neural substrate of prediction and reward. Science 275(5306):1593-9. https:// doi.org/10.1126/science.275.5306.1593. 
Selimbeyoglu A, Kim CK, Inoue M, Lee SY, Hong ASO, Kauvar I, and others. 2017. Modulation of prefrontal cortex excitation/inhibition balance rescues social behavior in. Sci Transl Med 9(401). https://doi.org/10.1126/scitranslmed. aah6733.

Siuda ER, Al-Hasani R, McCall JG, Bhatti DL, Bruchas MR. 2016. Chemogenetic and optogenetic activation of gas signaling in the basolateral amygdala induces acute and social anxiety-like states. Neuropsychopharmacology 41(8):2011-23. https://doi.org/10.1038/npp.2015.371.

Soutschek A, Burke CJ, Beharelle AR, Schreiber R, Weber SC, Karipidis II, and others. 2017. The dopaminergic reward system underpins gender differences in social preferences. Nat Hum Behav 1(11):819. https://doi.org/10.1038/ s41562-017-0226-y.

Spreckelmeyer KN, Krach S, Kohls G, Rademacher L, Irmak A, Konrad K, and others. 2009. Anticipation of monetary and social reward differently activates mesolimbic brain structures in men and women. Soc Cogn Affect Neurosci 4(2):158-65. https://doi.org/10.1093/scan/nsn051.

Stafford JM, Jarrett BR, Miranda-Dominguez O, Mills BD, Cain N, Mihalas S, and others. 2014. Large-scale topology and the default mode network in the mouse connectome. Proc Natl Acad Sci U S A 111(52):18745-50. https://doi. org/10.1073/pnas.1404346111.

Sternson SM and BL Roth. 2014. "Chemogenetic tools to interrogate brain functions." Annu Rev Neurosci 37:387-407. https://doi.org/10.1146/annurev-neuro-071013-014048.

Stuber GD, Hnasko TS, Britt JP, Edwards RH, Bonci A. 2010. Dopaminergic terminals in the nucleus accumbens but not the dorsal striatum corelease glutamate. J Neurosci 30(24):8229-33. https://doi.org/10.1523/ JNEUROSCI.1754-10.2010.

Tan S, Xiao Y, Yin HH, Chen AI, Soong TW, Je HS. 2018. Postnatal TrkB ablation in corticolimbic interneurons induces social dominance in male mice. Proc Natl Acad Sci U S A 115(42):E9909-15. https://doi.org/10.1073/ pnas. 1812083115 .

Tecuapetla F, Patel JC, Xenias H, English D, Tadros I, Shah F, and others. 2010. Glutamatergic signaling by mesolimbic dopamine neurons in the nucleus accumbens. J Neurosci 30(20):7105-10. https://doi.org/10.1523/ JNEUROSCI.0265-10.2010.

Tovote P, Lüthi A. 2012. Curbing fear by axonal oxytocin release in the amygdala. Neuron 73(3):407-10. https://doi. org/10.1016/j.neuron.2012.01.016.

Tsai H-C, Zhang F, Adamantidis A, Stuber GD, Bonci A, de Lecea L, and others. 2009. Phasic firing in dopaminergic neurons is sufficient for behavioral conditioning. Science 324(5930):1080-4. https://doi.org/10.1126/science. 1168878 .

van den Bos W, Vahl P, Güroğlu B, van Nunspeet F, Colins O, Markus M, and others. 2014. Neural correlates of social decision-making in severely antisocial adolescents. Soc Cogn Affect Neurosci 9(12):2059-66. https://doi. org/10.1093/scan/nsu003.

Van Overwalle F, D'aes T, Mariën P. 2015. Social cognition and the cerebellum: a meta-analytic connectivity analysis.
Hum Brain Mapp 36(12):5137-54. https://doi.org/10.1002/ hbm.23002.

Vazdarjanova A, Cahill L, McGaugh JL. 2001. Disrupting basolateral amygdala function impairs unconditioned freezing and avoidance in ats. Eur J Neurosci 14(4):709-18.

Viding E, McCrory E. 2019. Towards understanding atypical social affiliation in psychopathy. Lancet Psychiatry 6(5): 437-44. https://doi.org/10.1016/S2215-0366(19)30049-5.

Vogt BA, Paxinos G. 2014. Cytoarchitecture of mouse and rat cingulate cortex with human homologies. Brain Struct Funct 219(1):185-92. https://doi.org/10.1007/s00429-0120493-3.

Wallis JD. 2007. Orbitofrontal cortex and its contribution to decision-making. Annu Rev Neurosci 30:31-56. https:// doi.org/10.1146/annurev.neuro.30.051606.094334.

Wallis JD. 2011. Cross-species studies of orbitofrontal cortex and value-based decision-making. Nat Neurosci 15(1): 13-9. https://doi.org/10.1038/nn.2956.

Walsh JJ, Christoffel DJ, Heifets BD, Ben-Dor GA, Selimbeyoglu A, Hung LW, and others. 2018. 5-HT release in nucleus accumbens rescues social deficits in mouse autism model. Nature 560(7720):589-94. https:// doi.org/10.1038/s41586-018-0416-4.

Walton GE, Bower TGR. 1993. Newborns form 'Prototypes' in less than 1 minute. Psychol Sci 4(3):203-5. https://doi. org/10.1111/j.1467-9280.1993.tb00488.x.

Watson KK, Platt ML. 2012. Of mice and monkeys: using non-human primate models to bridge mouse- and humanbased investigations of autism spectrum disorders. J Neurodev Disord 4(1):21. https://doi.org/10.1186/18661955-4-21.

Watson TC, Becker N, Apps R, Jones MW. 2014. Back to front: cerebellar connections and interactions with the prefrontal cortex. Front Syst Neurosci 8:4. https://doi.org/10.3389/ fnsys.2014.00004.

Wang SS-H, Kloth AD, Badura A. 2014. The cerebellum, sensitive periods, and autism. Neuron 83(3):518-32. https://doi. org/10.1016/j.neuron.2014.07.016.

Wang W, Rein B, Zhang F, Tan T, Zhong P, Qin L, and others. 2018. Chemogenetic activation of prefrontal cortex rescues synaptic and behavioral deficits in a mouse model of 16p11.2 deletion syndrome. J Neurosci 38(26):5939-48. https://doi.org/10.1523/JNEUROSCI.0149-18.2018.

Wei D, Lee D, Cox CD, Karsten CA, Peñagarikano O, Geschwind DH, and others. 2015. Endocannabinoid signaling mediates oxytocin-driven social reward. Proc Natl Acad Sci U S A 112(45):14084-9. https://doi.org/10.1073/ pnas. 1509795112 .

Williams JH, Whiten A, Suddendorf T, Perrett DI. 2001. Imitation, mirror neurons and autism. Neurosci Biobehav Rev 25(4):287-95.

Winston JS, Strange BA, O’Doherty J, Dolan RJ. 2002. Automatic and intentional brain responses during evaluation of trustworthiness of faces. Nat Neurosci 5(3):277-83. https://doi.org/10.1038/nn816.

Wittmann MK, Lockwood, Rushworth MFS. 2018. Neural mechanisms of social cognition in primates. Annu Rev Neurosci 41:99-118. https://doi.org/10.1146/annurevneuro-080317-061450. 
Xiao L, Priest MF, Nasenbeny J, Lu T, Kozorovitskiy Y. 2017. Biased oxytocinergic modulation of midbrain dopamine systems. Neuron 95(2):368-84.e5. https://doi. org/10.1016/j.neuron.2017.06.003.

Yizhar O, Fenno LE, Davidson TJ, Mogri M, Deisseroth K. 2011. Optogenetics in neural systems. Neuron 71(1):9-34. https://doi.org/10.1016/j.neuron.2011.06.004.

Yizhar O, Fenno LE, Prigge M, Schneider F, Davidson TJ, O’Shea DJ, and others. 2011. Neocortical excitation/inhibition balance in information processing and social dysfunction. Nature 477(7363):171-8. https://doi.org/10.1038/nature10360.

Young L, Dodell-Feder D, Saxe R. 2010. What gets the attention of the temporo-parietal junction? an fMRI investigation of attention and theory of mind. Neuropsychologia 48(9):265864. https://doi.org/10.1016/j.neuropsychologia.2010.05.012.
Yuan M, Zhu H, Qiu C, Meng Y, Zhang Y, Shang J, and others. 2016. Group cognitive behavioral therapy modulates the resting-state functional connectivity of amygdala-related network in patients with generalized social anxiety disorder. BMC Psychiatry 16:198. https://doi.org/10.1186/ s12888-016-0904-8.

Zanon M, Novembre G, Zangrando N, Chittaro L, Silani G. 2014. Brain activity and prosocial behavior in a simulated life-threatening situation. Neuroimage 98:134-46. https:// doi.org/10.1016/j.neuroimage.2014.04.053.

Zheng J-J, Li S-J, Zhang X-D, Miao W-Y, Zhang D, Yao H, and others. 2014. Oxytocin mediates early experiencedependent cross-modal plasticity in the sensory cortices. Nat Neurosci 17(3):391-9. https://doi.org/10.1038/ nn. 3634 . 